\title{
FUNDAMENTOS ESTRATÉGICOS PROMOVENDO A CAPACIDADE DE INOVAÇÃO EM NEGÓCIOS TRADICIONAIS E DE IMPACTO SOCIAL
}

\author{
STRATEGIC FUNDAMENTS PROMOTING THE CAPACITY OF INNOVATION IN TRADITIONAL \\ BUSINESSES AND OF SOCIAL IMPACT
}

Resumo

Célia Maria Ronzan Mestre em Administração Universidade Nove de Julho - UNINOVE São Paulo, SP - Brasil celiaronzani@uol.com.br

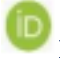

Priscila Rezende da Costa Doutora em Administração Universidade Nove de Julho - UNINOVE São Paulo, SP - Brasi priscilarezende@yahoo.com.br

A Capacidade de Inovação (CI) e os Fundamentos Estratégicos (FE) são elementos potencialmente relevantes à diferenciação dos Negócios Tradicionais (NT), pois podem contribuir para a geração de inovação tecnológica. No entanto, uma questão importante é investigar se esses elementos são igualmente importantes para os Negócios de Impacto Social (NIS) que geram inovação social. Nesse contexto, buscaram-se respostas para a questão de pesquisa, como os fundamentos estratégicos (FE) (missão, visão, valores e estrutura) podem contribuir para a capacidade de inovação (CI) de NT e NIS? A fim de buscar resposta a essa questão o objetivo desse estudo é investigar as contribuições dos FE para a mobilização de recursos que fomentam a CI em NT e aqueles que promovem Inovação Social. Nesta pesquisa, de natureza qualitativa e descritiva, adotou-se como método o estudo de caso múltiplo, sendo as unidades de análises: um NT, a BRAILE, e um NIS, o CREN. Os dados foram coletados a partir de entrevistas semiestruturadas e levantamento de documentos. Para a interpretação dos dados, adotou-se a análise de conteúdo com o auxílio do software Atlas.Ti, para a organização e codificação dos dados. Os principais resultados apontam que os FE em todas as suas subdivisões fomentaram a CI nas duas empresas. A pesquisa contribui para o entendimento de que os NIS precisam de uma estrutura organizacional estabelecida, como ocorre nos NT (com fins lucrativos).

Palavras-chave: Capacidade de inovação. Fundamentos estratégicos. Negócios tradicionais. Negócios de impacto social.

Abstract

Innovation Capacity (CI) and Strategic Foundations (FE) are elements potentially relevant to the differentiation of Traditional Business (NT) because they can contribute to the generation of technological innovation. However, an important highlight is to investigate whether these elements are equally important for the Social Impact Businesses (NIS) that generates social innovation. In this context, the research question was sought about how can strategic foundations (FE) (mission, vision, values, and structure) contribute to CI of NT and NIS? Therefore, we pursue in this study to investigate the contributions of FE to the mobilization of resources that foster IC in NT and those that promote social Innovation, as well. In this qualitative and descriptive nature research, a multiple case study method was adopted in two different businesses: BRAILE as a NT, and CREN as a business with a social impact. Data were collected from semi-structured interviews and document surveys. For data interpretation a content analysis was adopted into Atlas.Ti software that supports to organize and code the data. The main results show that the FE fostered CI in both companies. The research contributes to the understanding that NIS need an established organizational structure, as NT (for-profit).

Keywords: Innovation capacity. Strategic foundations. Traditional business. Social impact business.

Cite como

American Psychological Association (APA)

Ronzani, C. M., Costa, P. R., Paiva, E. M., \& Pingola, A. (2021, maio/ago.). Fundamentos estratégicos promovendo a capacidade de inovação em negócios tradicionais e de impacto social. Revista de Gestão e Projetos (GeP), 12(2), 56-84. https://doi.org/10.5585/gep.v12i2.17978. 


\section{Introdução}

A inovação é um dos grandes desafios enfrentados por diferentes organizações e vista como uma meta a ser atingida porque através dela é possível alcançar diferenciação e competitividade no mercado. No entanto, as organizações precisam ter capacidade de inovar, de transformar continuamente $\mathrm{o}$ conhecimento a fim de gerar resultados inovadores em benefício da empresa e de seus stakeholders (Neely et al., 2001; Lawson \& Samson, 2001), ou seja, têm que ter potencial para gerar uma saída inovativa (Neely \& Hii, 1988).

A "Capacidade de Inovação" (CI) é considerada um construto multidimensional (Tidd \& Bessant, 2008; Crossan \& Apaydin, 2010) por envolver dimensões organizacionais e individuais, e os Fundamentos Estratégicos (FE) (missão, visão, valores e estrutura) são elementos que podem ser relevantes à diferenciação nas organizações tradicionais, pois podem contribuir para a geração de inovação tecnológica (Saunila et al., 2014).

Os Negócios Tradicionais (NT) e as organizações sem fins lucrativos (Negócios de Inovação Social - NIS) podem guardar potenciais similaridades e distinções no que tange à CI, ou seja, no conjunto de habilidades de mobilização de recursos humanos, físicos, tecnológicos e financeiros, em prol da geração de inovações (Saunila \& Ukko, 2012) e, nesse sentido, os dois tipos de negócios possuem uma identidade institucional, através da declaração dos FE (Missão, Visão e Valores) bem como uma estrutura interna adequada para atender expectativas específicas para cada tipo de negócio), considerando os estudos de Desmidt et al. (2011). Sendo assim, a CI e os FE são elementos potencialmente relevantes à diferenciação do NT, pois podem contribuir para a geração de inovação tecnológica (Saunila et al., 2014). Cabe investigar se esses elementos são igualmente importantes para o NIS na promoção do valor social e, com ele, as inovações sociais.

Diferentes estudos foram realizados em torno do tema CI (Barney, 1991; Damanpour \& Gopalakrishnan, 2001; Gopalakrishnan, Shanti \& Damanpour, 1997), mas não há indícios de investigações empíricas sobre como $\mathrm{FE}$ (missão, visão, valores e estrutura) podem contribuir para a CI dos NT e do NIS. Na perspectiva de preencher essa lacuna, buscaram-se respostas para a seguinte questão de pesquisa: como o FE (missão, visão, valores e estrutura) contribui para a CI de negócios considerados tradicionais e aqueles voltados para a inovação social? Dessa maneira, o objetivo desse estudo é investigar as contribuições dos FE para a mobilização de recursos que fomentam a CI em NT e em Inovação Social.

Este estudo contribui para o avanço do conhecimento ao demonstrar que os FE podem contribuir para mobilizar recursos para impulsionar a CI especialmente quando se trata de negócios voltados para inovação social que também precisam de uma estrutura 
organizacional estabelecida, como ocorre nos NT (com fins lucrativos). A proposição central desta pesquisa é investigar se os FE (missão, visão e valores) podem estimular a CI em NT, resultando em inovação tecnológica e em negócios que promovam a inovação social, gerando valor social. Em função disso, para esse estudo, adotaram-se as dimensões dos FE, baseado em Lawson and Samson (2001) porque eles entendem que as subcategorias da CI são visão e estratégia -, como impulsionadores da CI seguindo o modelo de Saunila and Ukko (2012) que envolve o potencial, o processo e os resultados da inovação.

O artigo está organizado da seguinte forma, além desta seção introdutória, a segunda seção fornece a base teórica e a terceira a descrição metodológica. Na quarta seção apresentamos os resultados. E, por fim, a quinta seção aborda as implicações, limitações e direções para pesquisas futuras.

\section{Referencial teórico}

Essa pesquisa argumenta que os $\mathrm{FE}$ podem contribuir para a mobilização de recursos que fomentam a CI em NT e NIS. Dessa forma, nessa seção, são apresentados os fundamentos teóricos relativos aos construtos capacidade de inovação e os fundamentos estratégicos que dão suporte à pesquisa.

\subsection{Capacidade de inovação}

A CI compreende esforços para extrair conhecimentos provenientes do desenvolvimento equilibrado das atividades de explotation e exploration gerando novas ideias e novos produtos, processos e sistemas a fim de beneficiar a própria empresa e seus stakeholders (Lawson \& Samson, 2001; Kirner et al., 2009). Isso depende dos arranjos que ela cria ao lançar novas iniciativas que permitam alavancar efetivamente as dotações de recursos existentes da empresa (Ravichandran, 2018).

A fim de melhorar a CI, as empresas investem em Pesquisa e Desenvolvimento (P\&D) para acumular conhecimento (Afuah, 2002) e aquelas que têm maior Capacidade de organizar seus recursos podem estar mais abertas a novas ideias e, consequentemente, mais bem posicionadas para identificar novas oportunidades no mercado mais rápido e melhor que seus concorrentes (Ravichandran, 2018). A CI é considerada o determinante mais importante do desempenho da empresa (Mone et al., 1998) porque o resultado da inovação é o ponto final de sua busca intelectual (Crossan \& Apaydan, 2010). Dessa forma, alguns fatores são determinantes para o resultado, como por exemplo, os FE adotados (Lawson \& Samson, 2001).

A literatura apresenta inúmeros modelos teóricos consolidados para a implantação do processo da CI, cujo grau de complexidade e abrangência é elevado, se considerado o universo de estudo de cada inovação. Apresentamos alguns modelos que tratam sobre a capacidade de inovação das organizações propostos por Lawson and Samson (2001), Zawislak et al. (2012), Saunila 
and Ukko (2012) e Saunila et al. (2014) que permitem compreender as suas respectivas dimensões de análise.

O modelo de Lawson and Samson (2001) evidencia a CI como uma habilidade de inovadores de alto desempenho capaz de criar o potencial para um comportamento inovador em toda a organização e que deve ser gerenciada constantemente. A CI, segundo os autores, é constituída por dimensões distintas, porém complementares e, quando bem gerenciadas, tem maior probabilidade de alcançar inovação sustentável. Essas dimensões são a visão e estratégia, aproveitamento das competências, gestão da criatividade e de ideias, estrutura e sistemas organizacionais, cultura e clima, inteligência organizacional e gestão da tecnologia.

O modelo de Zawislak et al. (2012) parte de dois questionamentos: primeiro por quais motivos nem todas as empresas investidoras em capacidade tecnológica são inovadoras e o que permite que empresas que aplicam poucos recursos financeiros em tecnologia conseguem ser mais inovadoras do que aquelas que investem nela massivamente. A resposta tem relação com a CI dessas empresas que pode emergir de qualquer uma das funções básicas da organização e, não apenas, de uma capacidade tecnológica intermediada pela estrutura de P\&D ou do corpo técnico (Reichert et al., 2015). A formação da CI acontece pela junção de quatro capacidades complementares, de desenvolvimento tecnológico, de operações, de gerenciamento e de transação. A predominância de cada uma delas será responsável por um tipo diferente de inovação. Salienta-se que, quando criadas, as organizações já contam, principalmente, com as capacidades de desenvolvimento tecnológico e transacional e as outras são desenvolvidas à medida que elas amadurecem no mercado.

O terceiro modelo de Saunila and Ukko (2012), enfatiza que a inovação precisa ser medida constantemente a fim de compreender o seu potencial. A CI pode ser definida sob três dimensões-chave: (1) o potencial de inovação que consiste em fatores que afetam e interferem o estado atual da capacidade inovativa da empresa, melhorando ou piorando essa capacidade; (2) os processos de inovação que são entendidos como os sistemas e atividades que ajudam as empresas a utilizarem o potencial de inovação e, em consequência disso, produzirem inovações; e (3) os resultados dos processos de inovação que se caracterizam em novos produtos ou serviços (Saunila \& Ukko, 2012). Para fins de operacionalização dessa pesquisa, considera-se que a $\mathrm{CI}$, e suas três dimensões, abordam um conjunto de habilidades de uma organização, a fim de mobilizar recursos em prol da geração de inovação, tendo em vista que a gestão dos recursos pode diferenciar as organizações. Nesse sentido, os FE podem assumir relevância distintiva.

Por fim, o modelo de Saunila et al. (2014) que mede o relacionamento entre CI e performance organizacional. A CI compreende sete dimensões: (1) cultura de liderança 
participativa, (2) geração de ideias e estrutura organizacional, (3) clima organizacional e bemestar, (4) desenvolvimento do know-how, (5) regeneração, (6) conhecimento externo e (7) atividade individual. Consideram que a CI não possui apenas uma definição e construção.

\subsection{Fundamentos estratégicos}

A declaração da missão é considerada uma ferramenta de gestão que pode impactar positivamente no desempenho organizacional provavelmente não de maneira direta, mas influenciando as variáveis intervenientes que influenciam o desempenho ou interagem com outras variáveis impactando no desempenho (Patel et al., 2015) - ainda que essa influência seja pequena como nos achados de Desmidt et al. (2011).

As organizações costumam usar declarações de missão como um instrumento para criar valores comuns que irão guiar e inspirar os membros da organização, para aumentar ou garantir o comprometimento das partes interessadas, comunicar-se de forma eficaz e estabelecer um propósito principal de liderança em qualidade ou tecnologia (Desmidt et al., 2011). Por outro lado, uma corrente de estudiosos (Ireland \& Hitt, 1992; Bartkus et al., 2000; Bartkus \& Myron, 2008) consideram que as declarações de missão não criam um compromisso, mas descrevem declarações idealistas ao invés de se envolver em ações corretas (Bartkus \& Myron, 2008). Se por um lado a missão é uma responsabilidade assumida pela empresa, nascida de seus objetivos sociais, a visão é uma projeção idealista em um futuro indefinido, em uma posição madura e de sucesso que a empresa pode alcançar (Brătianu \& Bălănescu, 2008).

Os valores são reconhecidos como crenças duradouras que transcendem situações específicas e que orientam a seleção ou avaliação do comportamento (Rokeach, 1973). Por sua vez, a declaração de valores define as crenças que conduzirão as atividades da organização a fim de cumprir a missão e a visão envolvendo a valorização dos clientes, funcionários, outras partes interessadas e a comunidade refletindo o respeito, integridade, confiança, cuidado, excelência a moralidade (Aithal, 2016).

Nesse construto, este trabalho pesquisará as dimensões: (1) missão, (2) visão e valores e (3) estrutura (Lawon \& Samson, 2001; Desmidt et al., 2011). Considerando que nesse estudo buscaram-se respostas sobre como os FE (missão, visão, valores e estrutura) podem contribuir distintivamente para a CI de NT (lócus da inovação Tecnológica), e de NIS (da inovação Social) é importante entender a distinção entre a inovação social e tecnológica.

\subsection{Inovação tecnológica e social}

Tradicionalmente, a visão da inovação tem sido sustentada pela adoção de uma nova ideia, como forma de maximização do lucro. O conceito tem suas bases voltadas para o mercado e, em seu aporte teórico os estudos de Schumpeter (1934), “apontando que o 
desenvolvimento econômico, conduzido pela inovação é um processo dinâmico no qual as novas tecnologias substituem as antigas" (Farfus \& Rocha, 2007, p. 15). Inegavelmente, a tecnologia sempre esteve atrelada à inovação, sendo um condutor no processo de desenvolvimento. Essa lógica se caracteriza pela introdução de um novo bem, de novos métodos de produção, pela abertura de novos mercados, pela conquista de novas fontes de matérias-primas e insumos, ou pela criação de novas estruturas de mercado em uma indústria.

Por sua vez, a inovação social, refere-se à criação de resultados duradouros que trabalham no cumprimento de metas sociais e que funcionam para atender às necessidades prementes não satisfeitas e melhorar a vida das pessoas (Mulgan et al., 2007). Ou seja, são atividades e serviços inovadores que são motivados pela meta de atender uma necessidade social e que são, predominantemente, desenvolvidas e difundidas através de organizações cujos objetivos principais são o social (Mulgam et al., 2007). Elas alteram as relações, posições e regras através de um processo participativo, de troca e colaboração entre as partes interessadas (Voorberg et al., 2014). As suas raízes são respaldadas pela lacuna existente entre o que deveria haver, o que as pessoas precisam e o que é oferecido por governos e empresas privadas uma lacuna que é constantemente alargada pelo surgimento de novas tecnologias e novos conhecimentos científicos (Mulgan et al., 2007).

O conceito de inovação social se afasta do de inovação tecnológica por "beneficiar os seres humanos antes de tudo" (Bignetti, 2011) e promover a inclusão social. Eles se distinguem, principalmente, em função de sua finalidade, estratégia, lócus, processo de inovação e difusão do conhecimento gerado (Bignetti, 2011). Austin et al. (2006) discutem variáveis que explicam a diferença entre as empresas voltadas exclusivamente para o lucro e as empresas com fins sociais. São elas, (1) falha de mercado - surge quando as forças comerciais são incapazes de atender uma necessidade ou os resultados econômicos são ineficientes ou indesejáveis, gerando oportunidades para os empreendimentos sociais; (2) diferenças entre as missões e sua manifestação na gestão e na motivação dos colaboradores; (3) medidas de desempenho do impacto social. As principais diferenças estão evidenciadas na Figura 1. 
Figura 1 - Descrição das diferenças em aspectos da inovação tecnológica e inovação social

\begin{tabular}{|c|c|c|}
\hline Aspecto & Inovação Tecnológica & Inovação Social \\
\hline Finalidade & $\begin{array}{l}\text { Apropriação do valor; auto interesse dos grupos } \\
\text { econômicos (Santos, 2012). }\end{array}$ & $\begin{array}{l}\text { Criação do valor; interesse dos grupos sociais } \\
\text { e da comunidade (Santos, 2012). }\end{array}$ \\
\hline Estratégia & Busca de vantagem competitiva (Santos, 2012). & $\begin{array}{l}\text { Busca de cooperação para resolver questões } \\
\text { sociais (Santos, 2012). }\end{array}$ \\
\hline $\begin{array}{l}\text { Processo de } \\
\text { Inovação }\end{array}$ & $\begin{array}{l}\text { O processo se desenvolve por etapas } \\
\text { sequenciais, definidas e controladas por } \\
\text { ferramentas de gestão específicas. É gerenciado } \\
\text { de dentro para fora, isto é, pela introdução de um } \\
\text { novo processo de produção, produto ou serviço } \\
\text { dirigido ao mercado (Cooper \& Edgett, 2009). }\end{array}$ & $\begin{array}{l}\text { É um processo de construção social, de } \\
\text { geração de soluções, dependente da trajetória. } \\
\text { A concepção, o desenvolvimento e a } \\
\text { aplicação estão intimamente imbricados e são } \\
\text { realizados por meio da relação e da } \\
\text { cooperação entre todos os atores envolvidos. } \\
\text { Significa um processo de aprendizagem } \\
\text { coletivo, que se baseia no potencial dos } \\
\text { indivíduos e dos grupos, que adquirem as } \\
\text { capacidades necessárias para realizar as } \\
\text { transformações sociais (Bignetti, 2011). }\end{array}$ \\
\hline $\begin{array}{l}\text { Difusão do } \\
\text { Conhecimento } \\
\text { Gerado }\end{array}$ & $\begin{array}{l}\text { Mecanismos de proteção intelectual procuram } \\
\text { impedir que uma ideia ou uma tecnologia } \\
\text { desenvolvida e aplicada por uma empresa possa } \\
\text { ser copiada e utilizada por concorrentes. As } \\
\text { inovações tecnológicas são de todas as formas } \\
\text { blindadas, de modo a permitir um período de } \\
\text { exclusividade e um prazo para a obtenção dos } \\
\text { lucros extraordinários, preconizados por } \\
\text { Schumpeter (1961). }\end{array}$ & $\begin{array}{l}\text { As inovações sociais seguem mecanismos de } \\
\text { difusão que favorecem a replicação e a } \\
\text { expansão dos resultados a outras } \\
\text { comunidades. Assim, a transposição de } \\
\text { experiências de uma comunidade para outra, } \\
\text { ou entre organizações, é prática comum e } \\
\text { alimentada por centros de inovação social, } \\
\text { por redes organizacionais e por diferentes } \\
\text { fóruns de discussão de ideias e de } \\
\text { apresentação de casos (Bignetti, 2011). }\end{array}$ \\
\hline
\end{tabular}

Fonte: adaptado de Schumpeter (1961), Cooper and Edgett (2009), Bignetti (2011) e (Santos, 2012).

Isso posto, é importante compreender que as NIS podem realizar ações de cunho social de diversas formas: no controle de suas operações, visando a preservação do ambiente; no desenvolvimento de projetos junto às comunidades; e na criação de fundações ou de outros arranjos institucionais.

Assume-se prepositivamente, que o NT é lócus da inovação tecnológica e o NIS da inovação social (Cajaiba-Santana, 2014; Camelo et al., 2011; Phillis et al., 2015), seguindo, portanto, a abordagem neoschumpeteriana de que o processo inovativo tem a empresa como seu agente central.

\section{Procedimentos metodológicos}

Essa pesquisa tem caráter qualitativo (Godoy, 1995; Minayo, 2011) e descritivo (Martins \& Theóphilo, 2009) adotando como método o estudo de caso múltiplo (Creswell, 2007; Yin, 2011) e tem como objetos de análises uma NT, a BRAILE (vencedora do prêmio "FINEP de Inovação", categoria Média Empresa) e uma NIS, o Centro de Recuperação e Educação Nutricional - CREN (vencedor do prêmio "Empreendedor Social" do Jornal Folha de S. Paulo). A decisão por realizar o estudo nessas duas unidades de análises se deu em razão de que as inovações geradas para saúde 
obtiveram distinção de mérito (incluindo inovações tecnológicas e sociais), em virtude do tamanho dos negócios (organizações de médio porte) e da sua finalidade (negócios de inovação tecnológica e social).

Os dados primários foram coletados a partir de 14 entrevistas semiestruturadas (Martins \& Theóphilo, 2009; Trivinos, 1987), realizadas com diretores e gestores de recursos humanos da BRAILE e do CREN, gestores de $P \& D \& I$ e funcionários que integram a equipe de P\&D\&I em que foram investigadas evidências sobre a CI, levando-se em consideração a influência dos FE. Essas entrevistas foram realizadas presencialmente, gravadas e transcritas para registro e, posterior interpretação das evidências. Foi também realizado um levantamento documental nos negócios investigados usando um roteiro para análise documental.

Os dados secundários foram coletados em relatórios na área de recursos humanos sobre projetos desenvolvidos nos últimos 2 anos pela área de $\mathrm{P} \& D \& I$ que resultaram em produtos ou processos inovadores. Vale esclarecer que a pesquisa de campo resultou em 10 horas e 30 minutos de gravação e 114 páginas de transcrição, além do levantamento de documentos, que resultaram em duas páginas de compilação das evidências coletadas. A Figura 2 apresenta a matriz metodológica da pesquisa.

Figura 2 - Matriz metodológica

\begin{tabular}{|c|c|c|}
\hline \multicolumn{2}{|c|}{ Matriz Metodológica } & Autores \\
\hline Natureza da pesquisa & Qualitativa & $\begin{array}{l}\text { (Godoy, 1995b) } \\
\text { (Martins \& Theóphilo, 2009) } \\
\text { (Minayo, 2011) }\end{array}$ \\
\hline Abordagem metodológica & Descritiva & (Martins \& Theóphilo, 2009) \\
\hline Paradigma & Interpretativismo & (Martins \& Theóphilo, 2009) \\
\hline Método & Estudo de caso múltiplo & $\begin{array}{l}\text { (Yin, 2011) } \\
\text { (Creswell, 2007) } \\
\text { (Godoy, 1995b) }\end{array}$ \\
\hline Unidade de análise & $\begin{array}{l}2 \text { casos (um negócio } \\
\text { tradicional e um negócio com } \\
\text { impacto social). }\end{array}$ & $\begin{array}{l}\text { Organizações vencedoras do prêmio } \\
\text { "Empreendedor Social" do Jornal } \\
\text { Folha de S. Paulo ou do prêmio } \\
\text { "FINEP de Inovação", nas categorias } \\
\text { Média Empresa, Tecnologia Assistiva } \\
\text { e Tecnologia Social. }\end{array}$ \\
\hline $\begin{array}{l}\text { Procedimentos de coleta de } \\
\text { dados }\end{array}$ & $\begin{array}{l}\text { Entrevistas semiestruturadas e } \\
\text { levantamento documental. }\end{array}$ & 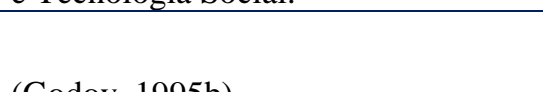 \\
\hline $\begin{array}{l}\text { Instrumentos de coleta de } \\
\text { dados }\end{array}$ & $\begin{array}{l}\text { Roteiros de entrevista e de } \\
\text { investigação documental. }\end{array}$ & (Godoy, 1995b) \\
\hline Análise dos dados & $\begin{array}{l}\text { Análise de conteúdo das } \\
\text { entrevistas e documentos } \\
\text { coletados e utilização do } \\
\text { software Atlas Ti. na } \\
\text { organização e codificação dos } \\
\text { dados brutos. }\end{array}$ & $\begin{array}{l}\text { (Godoy, 1995a) } \\
\text { (Minayo, 2011) }\end{array}$ \\
\hline
\end{tabular}

Fonte: Elaborada pelos autores. 
De forma específica, na análise de conteúdo, foram identificadas: inferências confiáveis de dados e informações, com respeito a determinado contexto e a partir dos discursos escritos ou orais de seus atores e/ou autores; a essência de um texto, nos detalhes das informações, dados e evidências disponíveis. Salienta-se que não se trabalha em tal análise somente com o texto, mas com detalhes do contexto. Por isso, ela pode ser utilizada tanto para fins exploratórios (de descoberta) quanto de verificação (confirmando, ou não, proposições e evidências) (Martins \&
Theóphilo, 2009). Destaca-se a utilização do software Atlas Ti (Paulus et al., 2019) que possibilitou a organização e a recuperação de informações relacionadas à ideia ou ao conceito subjacente às categorias de análise, criadas pelo pesquisador - procedimento importante para estruturá-las e validá-las empiricamente no processo de retorno aos dados qualitativos. Nessa pesquisa, essas categorias foram definidas como CI e FE. No protocolo de pesquisa (Figura 3) consta a descrição, de forma sequencial, das ações realizadas no decorrer da pesquisa de campo.

Figura 3 - Protocolo de pesquisa

\begin{tabular}{|l|l|}
\hline \multicolumn{1}{|c|}{ Etapas da Pesquisa } & \multicolumn{1}{c|}{ Descrição Operacional } \\
\hline $\begin{array}{l}\text { Selecionar um negócio tradicional e um negócio de } \\
\text { impacto social. }\end{array}$ & $\begin{array}{l}\text { Análise dos negócios vencedores do Prêmio FINEP de } \\
\text { Inovação e do Prêmio Empreendedor Social. }\end{array}$ \\
\hline $\begin{array}{l}\text { Contatar as organizações, apresentando o projeto } \\
\text { de pesquisa, convidando-as a nele participar. }\end{array}$ & $\begin{array}{l}\text { Envio de e-mail e/ou ligação telefônica para confirmação } \\
\text { do interesse em participar da pesquisa. }\end{array}$ \\
\hline $\begin{array}{l}\text { Coleta de dados primários junto aos diretores dos } \\
\text { negócios selecionados. }\end{array}$ & $\begin{array}{l}\text { Entrevista semiestruturada com diretores dos negócios } \\
\text { selecionados. }\end{array}$ \\
\hline $\begin{array}{l}\text { Coleta de dados primários junto aos gestores de de } \\
\text { RH dos negócios selecionados. }\end{array}$ & $\begin{array}{l}\text { Entrevista semiestruturada com os gestores de RH dos } \\
\text { negócios selecionados. }\end{array}$ \\
\hline $\begin{array}{l}\text { Coleta de dados primários junto aos gestores de } \\
\text { P\&D\&I dos negócios selecionados. }\end{array}$ & $\begin{array}{l}\text { Entrevista semiestruturada com os gestores de P\&D\&I } \\
\text { dos negócios selecionados. }\end{array}$ \\
\hline $\begin{array}{l}\text { Coleta de dados primários junto aos funcionários } \\
\text { que atuam nas equipes de P\&D\&I dos negócios } \\
\text { selecionados. }\end{array}$ & $\begin{array}{l}\text { Entrevista semiestruturada com funcionários que atuam } \\
\text { nas equipes de P\&D\&I dos negócios selecionados. }\end{array}$ \\
\hline $\begin{array}{l}\text { Levantamento de dados secundários, a partir de de } \\
\text { documentos do RH e do P\&D\&I. }\end{array}$ & $\begin{array}{l}\text { Compilação de evidências coletadas nos documentos } \\
\text { fornecidos pelo RH e pelo P\&D\&I. }\end{array}$ \\
\hline $\begin{array}{l}\text { Análise dos dados coletados, buscando estabelecer } \\
\text { relação com a questão de pesquisa e objetivos. }\end{array}$ & $\begin{array}{l}\text { Análise das evidências coletadas e elaboração das } \\
\text { discussões e conclusões da pesquisa. }\end{array}$ \\
\hline
\end{tabular}

Fonte: Elaborada pelos autores.

\section{Resultados e discussões}

A codificação dos dados no Atlas.Ti resultou em 381 citações vinculadas a 13 códigos, ou seja, foram identificadas 381 evidências relacionadas aos componentes de análise do estudo. Vale destacar que dos 13 códigos evidenciados (componentes das categorias), 7 emergiram do campo (códigos 
assinalados com asterisco na Tabela 1) e 6

tinham sido previstos no protocolo de pesquisa

(Tabela1).

Tabela 1 - Co-ocorrência dos códigos

\begin{tabular}{|c|c|c|c|c|c|c|c|c|c|c|c|c|}
\hline $\begin{array}{c}\text { Categorias de } \\
\text { Análise }\end{array}$ & & $\begin{array}{l}\text { Componentes } \\
\text { (códigos) }\end{array}$ & $\begin{array}{c}\text { Grau de } \\
\text { Fundamentação } \\
\text { (quantidade de } \\
\text { citações) }\end{array}$ & 1 & 2 & 3 & 4 & 5 & 6 & 7 & 8 & 9 \\
\hline \multirow{6}{*}{ FE } & 1 & $\begin{array}{l}\text { Autoavaliação } \\
*\end{array}$ & 9 & 0,00 & 0,00 & 0,10 & 0,00 & 0,00 & 0,00 & 0,00 & 0,00 & 0,00 \\
\hline & 2 & $\begin{array}{l}\text { Estrutura e } \\
\text { Estratégia de } \\
\text { P\&D\&I }\end{array}$ & 53 & 0,00 & 0,00 & 0,00 & 0,06 & 0,01 & 0,05 & 0,01 & 0,00 & 0,00 \\
\hline & 3 & Feedback* & 24 & 0,10 & 0,00 & 0,00 & 0,00 & 0,00 & 0,00 & 0,00 & 0,03 & 0,00 \\
\hline & 4 & $\begin{array}{l}\text { Formação da } \\
\text { Equipe de } \\
\text { projetos de } \\
\text { P\&D\&I* }\end{array}$ & 19 & 0,00 & 0,06 & 0,00 & 0,00 & 0,00 & 0,00 & 0,02 & 0,03 & 0,00 \\
\hline & 5 & $\begin{array}{l}\text { Missão, Visão } \\
\text { e Valores }\end{array}$ & 52 & 0,00 & 0,01 & 0,00 & 0,00 & 0,00 & 0,00 & 0,00 & 0,00 & 0,00 \\
\hline & 6 & $\begin{array}{l}\text { Requisitos de } \\
\text { Avaliação dos } \\
\text { Resultados de } \\
\text { P\&D\&I }\end{array}$ & 12 & 0,00 & 0,00 & 0,03 & 0,03 & 0,00 & 0,00 & 0,00 & 0,00 & 0,00 \\
\hline \multirow{3}{*}{ CI } & 11 & $\begin{array}{l}\text { Potencial de } \\
\text { Inovação }\end{array}$ & 36 & 0,00 & 0,05 & 0,00 & 0,00 & 0,00 & 0,00 & 0,00 & 0,00 & 0,00 \\
\hline & 12 & Processos & 48 & 0,00 & 0,01 & 0,00 & 0,02 & 0,00 & 0,00 & 0,00 & 0,00 & 0,01 \\
\hline & 13 & Resultados & 29 & 0,00 & 0,00 & 0,00 & 0,00 & 0,00 & \begin{tabular}{|l|l|}
0,00 \\
\end{tabular} & 0,01 & 0,00 & 0,02 \\
\hline
\end{tabular}

Nota: *Novos componentes (códigos) que emergiram do campo.

Fonte: Elaborada pelos autores, com auxílio do software Atlas Ti.

Foi analisada também a coocorrência de todos os códigos como evidência para relacioná-los. A Tabela 1 de coocorrência com todos os códigos, evidenciando a presença de unidades linguísticas (citações, ou seja, fragmentos de texto que deram significado ao fenômeno) que ocorreram, simultaneamente, em um mesmo contexto de análise. Sendo assim, relacionamos os códigos levando em consideração os seus maiores níveis de 
coocorrência (células destacadas na Tabela 1).

Foram realizadas análises intra-caso para as categorias de análise FE e CI.

A categoria FE é composta agora pelos seguintes componentes: missão, visão, valores e estrutura (inicialmente proposto) $\mathrm{e}$ autoavaliação, feedback, formação de equipe de projetos de P\&D\&I e Requisitos de Avaliação de resultados de $\mathrm{P} \& \mathrm{D} \& \mathrm{I}$ (surgidas no processo de análise). A categoria CI é composta pelos componentes: potencial de inovação, processos e resultados.

\subsection{Fundamento estratégicos}

A rede da Figura 4 apresenta os seis componentes relacionados à categoria "FE"

Figura 4 - Rede com os componentes relacionados à categoria "FE"

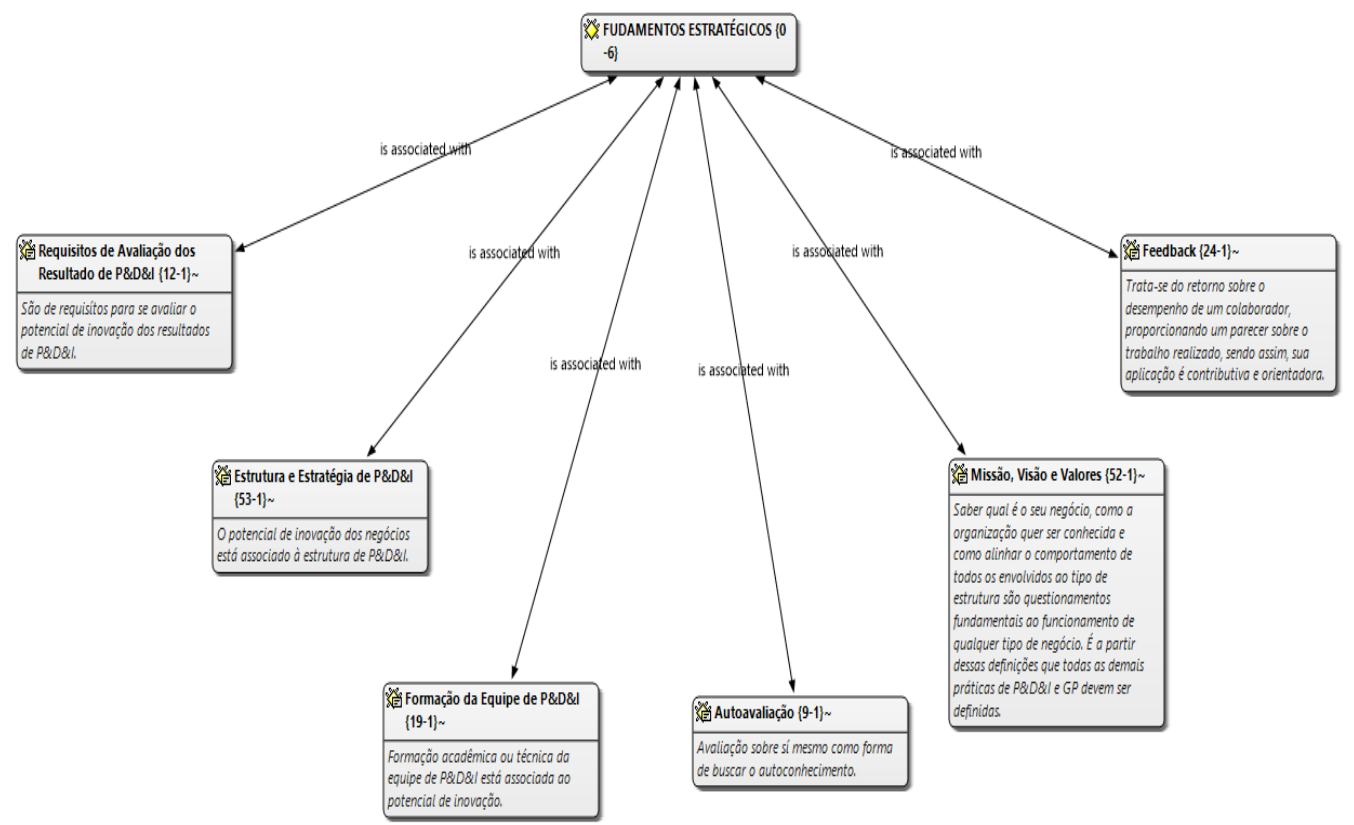

Fonte: Dados da pesquisa.

\subsubsection{Missão, visão e valores}

A Missão da BRAILE é aplicar Ciência, Inovação, Liderança e Tecnologia na criação e fabricação de produtos e equipamentos médicos. Sua Visão é ser uma empresa líder de mercado, no Brasil, e referência internacional, em produtos e equipamentos médicos. Entre os Valores da empresa, os Clientes são sua razão de existir; os Colaboradores, fundamentais ao sucesso; a Integridade, representada pelo cumprimento das leis e princípios morais; os Resultados, são quem geram valor para os clientes; a Excelência é a busca da inovação, "fazendo certo" desde a primeira vez; a Execução, responsável pelo "fazer acontecer" o compromisso pela palavra dada, a resposta ágil e a realização das metas; finalmente, o 
Desenvolvimento Sustentável é quem assegura equilíbrio entre lucro econômico, exercício da cidadania, preservação da natureza e respeito ao meio ambiente.

Na BRAILE missão, visão e valores atuam como sinalizadores para o todos os funcionários, em especial, para desempenho das equipes de projetos de P\&D\&I, na medida em que avaliam a prática e resultados obtidos e os comparam com o que é esperado. É fomentada pela atuação direta do fundador, agindo como modelo e do retorno financeiro obtido (BRAILE).

No CREN, a missão oficial da entidade, difundida por escrito internamente e por meio do seu site, é "enfrentar a subnutrição e a obesidade, nutrindo corpo, mente e relações para o desenvolvimento integral da pessoa e da família”, que estejam em condições de elevada vulnerabilidade. Assim como a missão, os valores também estão no site da instituição e são descritos como "retidão, respeito à pessoa, adequação à realidade, valorização do repertório e fazer com". Por sua vez, a Visão é descrita por intermédio de declarações de "Nosso Ofício" e "Nossa atuação". O Ofício da entidade é "educar, cuidar e nutrir para a vida"; e a atuação, se manifesta como sendo "a nutrição adequada das pessoas atendidas, alcançada por meio de três pilares: Assistência, Multiplicação, Pesquisa e Formação". Há uma variável, notada nas entrevistas, mas que não está escrita na Missão: a condição social da criança subnutrida, oriunda de situações de elevada vulnerabilidade.
No CREN, a missão, visão e valores também atuam como norteadores para as tomadas de decisões por parte da gestão. A estrutura é diferente da adotada pela BRAILE, em razão do seu foco principal que são as crianças subnutridas em situação de vulnerabilidade.

Abaixo, seguem trechos das entrevistas que sustentam as análises apresentadas.

Atenção constante da entidade em melhorar o serviço, quer dizer, isso está escrito na Missão, Visão e Valores, mas assim, além de estar escrito, tem uma conotação concreta do dia a dia da entidade pelo fato de que a gente quer, da melhor formal possível, assistir as pessoas que a gente assiste. (Código 10 do CREN).

Nossa Missão está muito alinhada ao cotidiano e com as atividades. A gente parte da realidade. Uma das premissas do CREN é olhar para a realidade. (Código 10 do CREN).

Então, a Missão aparece que está muito dentro das pessoas e fazem as pessoas se comprometerem com a empresa. (Código 3, da BRAILE)

A atuação da BRAILE se caracteriza por ações que promovem a vida, asseguram o equilíbrio entre o lucro econômico, o exercício da cidadania, a preservação da natureza e o respeito ao meio ambiente (Código 3, da BRAILE).

Segundo Desmidt et al. (2011), a declaração de missão, visão e valores favorece a empresa e apresenta uma relação positiva, embora pequena, com as medidas de desempenho organizacional, no que tange aos aspectos financeiros. A magnitude do relacionamento, contudo, é influenciada pelas decisões de operacionalização.

\subsubsection{Estrutura e estratégias de P\&D\&I}

O potencial de inovação dos negócios está associado à estrutura de P\&D\&I (significado que emergiu do campo). O

.


departamento de P\&D\&I, na BRAILE é composto por profissionais especializados, com formação acadêmica de nível superior, pósgraduação e/ou mestrado, que ocupam as funções de Gerente de P\&D\&I (1) e Coordenadores de Área (4). A maioria dos profissionais está há mais de 10 anos na empresa, tendo passado por funções hierárquicas inferiores, porém relacionadas às que estão desempenhando hoje. Há parcerias com as IES do Brasil e do exterior, que realizam estudos correlatos, e do Instituto Dr. Domingos Braile, também voltado à pesquisa na área de especialidade da empresa.

No CREN, devido à característica do negócio, não há uma estrutura formal de P\&D\&I, mas profissionais de formação variadas como médicos, psicólogos, nutricionistas, pedagogos, educadores físicos, entre outros, desempenham funções equivalentes. $\mathrm{Na}$ pesquisa foram considerados como equipe de projetos de P\&D\&I 1 gerente e 4 profissionais. Há, também, parcerias com pesquisadores de universidades para a realização de atividades de pesquisa.

$\mathrm{Na}$ sequência, estão reproduzidos trechos das entrevistas que ilustram a argumentação acima, bem como uma visão de rede, com algumas citações, recuperadas a partir do software Atlas.Ti (Figura 5).

Não é uma questão só de complementar, mas de ter espaços na estrutura que confirmem para o colaborador que aquela coisa é importante, que precisa ser feita daquela forma. É aí o desafio maior. (Código 8 do CREN).

Nossa equipe aumentou nas periferias. (Código 9, do CREN).

A área de P\&D\&I está em nível de gerência. (Código 1, da BRAILE).

Eu tenho uma equipe de 10 pessoas, uma equipe multifuncional. (Código 2, da BRAILE).

Figura 5 - Visão de rede que representa algumas citações associadas ao componente "estrutura e estratégia de P\&D\&I"

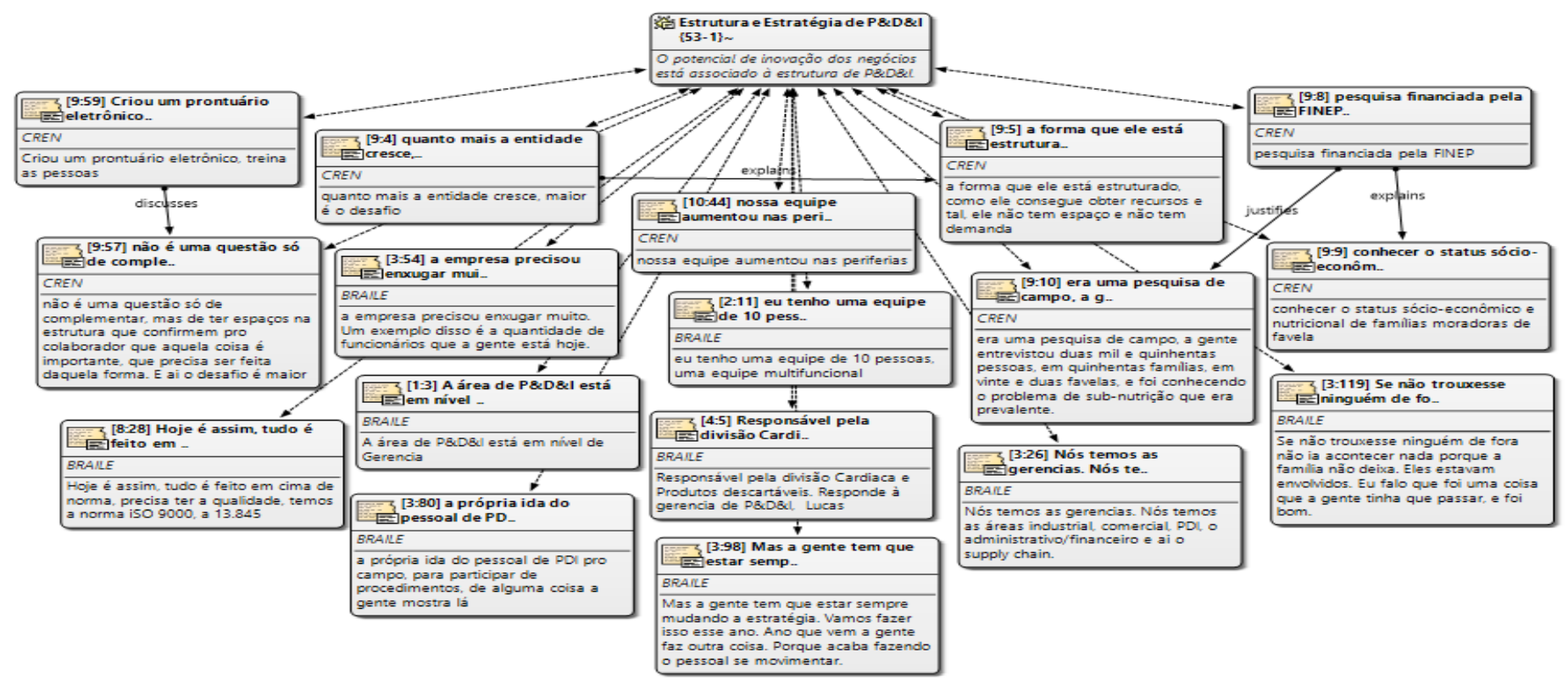

Fonte: Dados da pesquisa. 


\subsection{3 $\underline{\text { Autoavaliação }}$}

Quanto ao componente autoavaliação (avaliação sobre si mesmo, como forma de autoconhecimento - significado que surgiu no campo), tanto na BRAILE como no CREN, o grau de cobrança e preocupação com o alinhamento do desempenho ao esperado pela gestão do negócio é elevado dentro das equipes de projetos de P\&D\&I. Naturalmente, há recorrentes autoavaliações que dizem respeito a alguma não conformidade quanto aos resultados, ao feedback de colegas ou do gestor, e mesmo uma preocupação pessoal perante as mudanças.

Seguem trechos de falas dos

entrevistados que evidenciam essa constatação, recuperadas a partir do software Atlas.Ti.

Eu cobro muito essa questão de comprometimento do pessoal que trabalha comigo. Muitas vezes com o meu comprometimento mesmo. Eu sei que muitas vezes ninguém é 100\%. (Código 2, da BRAILE)

Preciso ter uma noção de onde, às vezes, estou me dedicando, colocando minhas energias, o que preciso melhorar, muito importante o feedback. (Código 5, da BRAILE)

O nosso nível de exigência vai aumentando um pouco e a gente vai ficando mais exigente, por se tratar de um dinheiro tão suado. Hoje a gente trabalha numa ONG com baixa pobreza e aposta na educação. Se eu não tenho um colaborador que tenha essa clareza, parece uma antítese, o paradoxo que a gente vive aqui. (Código 9, do CREN)

\subsubsection{Feedback}

Feedback é aqui tratado como um parecer sobre um trabalho realizado, o retorno sobre o desempenho de um colaborador e sua aplicação, portanto, é contributiva e orientadora (significado que emergiu do campo). A partir desse entendimento, na BRAILE e no CREN o feedback entre os membros da equipe de projetos de P\&D\&I é uma prática comum. A opinião de um terceiro, relevante ao processo, é bem-vinda, pois sinaliza se o caminho adotado levará ao resultado esperado. Alguns cuidados são tomados ao dar esse feedback sobre o comportamento declarados nas entrevistas pelas lideranças: "elogios são feitos em público e ajustes de atitudes, dados reservados". O feedback, feito na presença de todos, é relevante para o projeto e a equipe, por isso, é uma prática constante e acolhida com satisfação.

Abaixo, estão trechos das respostas, dadas durante as entrevistas, que exemplificam esse componente.

A gente pode falar de tudo com a pessoa, mas tem a maneira de falar, tem o jeito, tem a hora, e começando, assim, pela S. Ela tem isso. (Código 14, do CREN)

A conversa, muitas vezes, o feedback é oportuno, ajuda muito as pessoas. Eu tento me policiar muito de não dar o feedback na frente de mais de uma pessoa, porque acho que isso, muitas vezes, é ruim, principalmente quando o feedback é para chamar a atenção. Todo feedback que é um elogio, eu procuro, na maioria das vezes, fazer em público, para mostrar que uma atividade foi realizada com sucesso, e mostrar também, que, olha, você está vendo? Faça, que também tem esse reconhecimento. (Código 4, da BRAILE)

Sempre positivo, seja feedback bom ou ruim, mas sempre sabe que é uma forma de você ter uma visão externa, alguém está vendo o seu desempenho e como está tratando as atividades, e aceitar isso como positivo, sempre positivo. (Código 2, da BRAILE).

\subsubsection{Formação da equipe de P\&D\&I}

Entende-se, para efeito deste trabalho, formação acadêmica da equipe de $P \& D \& I$ como associação ao potencial de inovação (significado que emergiu do campo). Dessa 
forma, na BRAILE, todos os funcionários entrevistados da equipe de $\mathrm{P} \& \mathrm{D} \& \mathrm{I}$ possuem, no mínimo, formação superior, sendo a maioria em Engenharia Mecânica ou curso específico, relacionado à sua área de atuação, como Biofísica, por exemplo. Para eles, as inovações requerem uma busca constante de informação e atualização, por isso, dois deles estão cursando o Mestrado em Engenharia. Trechos das entrevistas com a equipe da BRAILE confirmam essas informações:

O pessoal tinha uma escolaridade mais baixa no passado. Foi por isso que acontecia também a rotatividade. (Código 3, da BRAILE)

Sim, o caminho não é pegar o bom gestor e capacitar ele em eletrônica. O caminho é o contrário, o caminho é pegar alguém que seja bom em eletrônica e tentar moldá-lo para fazer parte da gestão. (Código 2, da BRAILE)

Agora a gente tem mais esse foco de pessoal de mestrado, doutorado, com inglês já fluente. (Código 3, da BRAILE)

No CREN, a formação acadêmica da equipe de P\&D\&I é mais diversificada, considerando os vários fatores que influenciam a causa-fim, isto é, a nutrição. Por lidarem com pessoas, as habilidades sociais, aliadas ao conhecimento técnico específico da função, é a combinação ideal. Trechos das entrevistas feitas com a equipe do CREN confirma esses fatos.

Nutrição é multifatorial, então os trabalhos e as pesquisas não são feitos só por nutricionistas, tem outros profissionais. (Código 10, do CREN)

Formação na vida, sei lá, exposta, isto ajuda, pode favorecer a inovação. (Código 8, do CREN)

A maioria são nutricionistas, têm também educador físico, psicólogos, enfim, são diversos (Código 10, do CREN)

\subsubsection{Requisitos de avaliação dos resultados de P\&D\&I}

Esse é o último componente da categoria FE, que emergiu do campo a partir da análise, e indica o potencial de inovação da empresa. Partindo desse entendimento, na BRAILE, a avaliação dos resultados se dá pelo registro na ANVISA ou a abertura do Cadastro, dependendo do produto, seguido pela comercialização e pelo protocolo de acompanhamento do produto no paciente. A empresa possui certificações ISO e outras, inerentes ao tipo de atividade, que norteiam todo o processo. Por sua vez, no CREN, a avaliação é um pouco mais complexa, porque, embora seja evidente o alcance do objetivo final - verificar se a criança recuperou peso e o adolescente o perdeu, as etapas que antecedem essa constatação precisam ser devidamente monitoradas, pois envolvem uma série de fatores favorecedores ou impeditivos do resultado, como adesão da família ao tratamento.

Abaixo, estão alguns trechos de entrevistas com a equipe de P\&D\&I da BRAILE e do CREN, para ilustrar a explanação acima, bem como uma visão de rede, com algumas citações, recuperadas a partir do software Atlas.Ti (Figura 6). 
Existe uma sistematização do trabalho que vem dessa herança acadêmica da instituição. Então você tem indicadores que você olha todo ano, então no ano de 2017 as crianças que estiveram ao menos $\mathrm{x}$ consultas, quanto que evoluíram ou não evoluíram em relação ao estado nutricional? Ou, por exemplo, quando eu falava que o psicólogo tinha quatro meses de fila de espera, como a gente lida com isso? A gente vai contratar mais psicólogo ou vai pensar em alternativas? Então a instituição começou a investir, a olhar. A própria pesquisa nasce de uma demanda e eu entendo isso como um feedback, como um reconhecimento de um olhar que partiu de indicadores. (Código 11, do CREN)
Nos indicadores, a gente avalia a quantidade de visitas que foram feitas, porque a gente vai nas casas das famílias e verifica qual o peso daquela criança, o peso no primeiro semestre e o peso no segundo semestre, como está a gestão de alimentos daquela criança, qual o desenvolvimento pedagógico para aquela criança, para a idade. (Código 10, do CREN)

Figura 6 - Visão de rede que representa algumas citações associadas ao componente "requisitos de avaliação dos resultados de P\&D\&I"

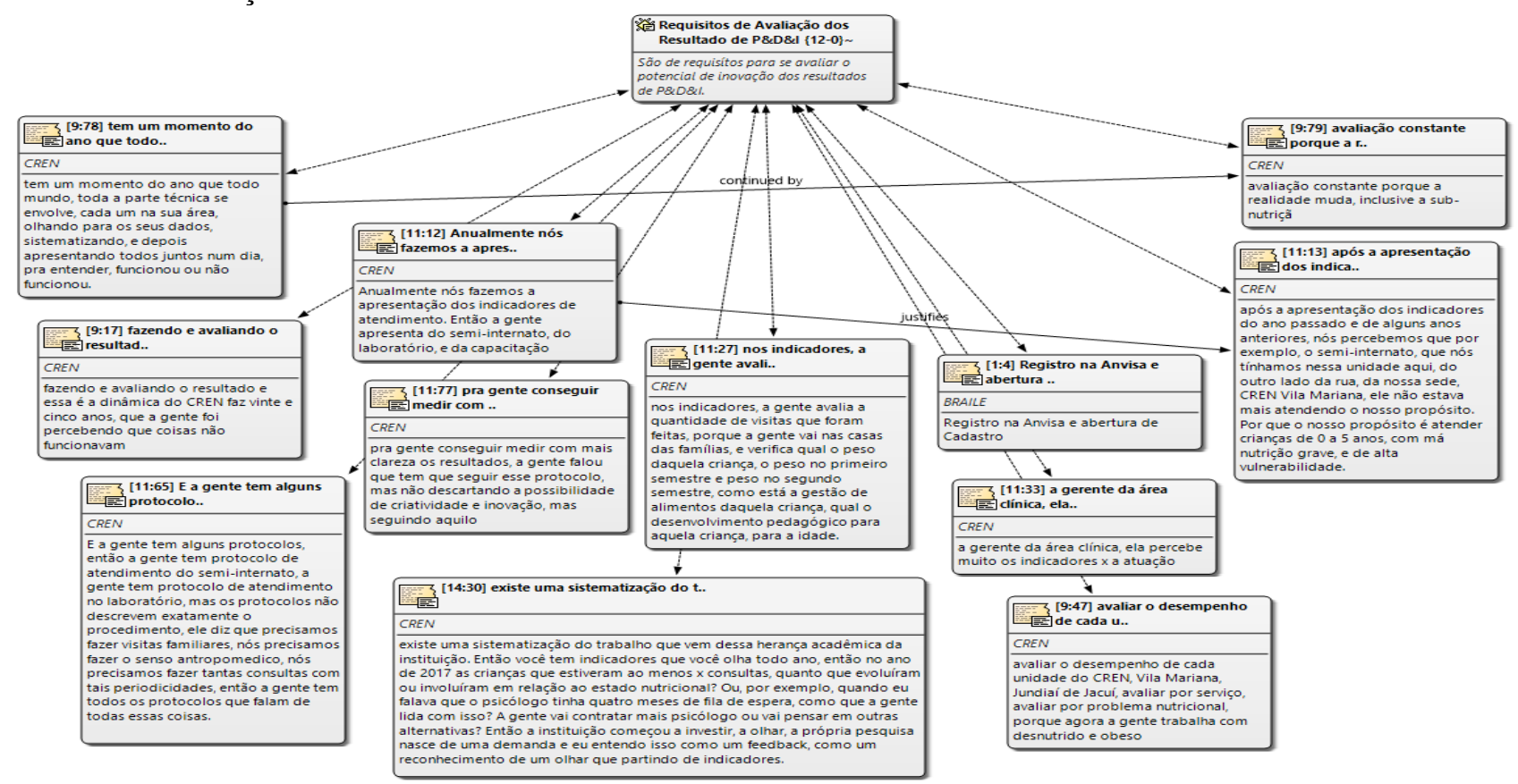

Fonte: Dados da pesquisa.

\subsection{Capacidade de inovação}

Para analisar a categoria central "CI", foram considerados os seguintes componentes: Potencial de Inovação, Processo e Resultados, conforme a Figura 7. 
Figura 7 - Rede com os componentes relacionados à categoria central "CI"

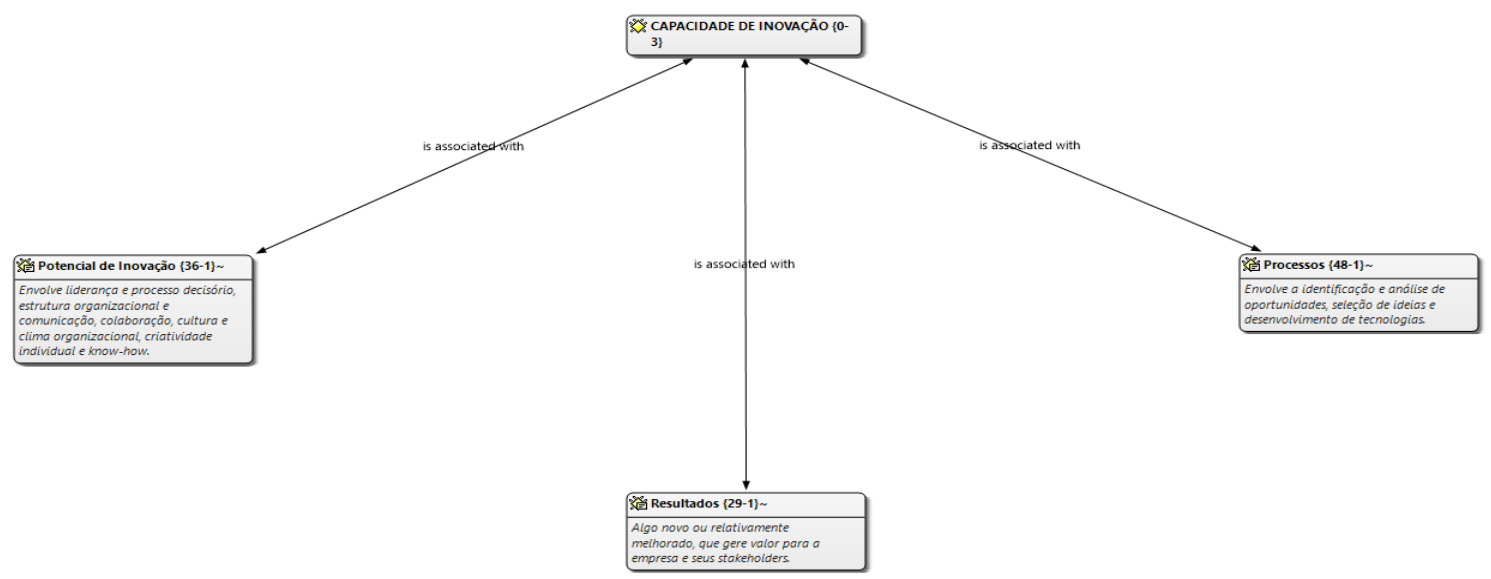

Fonte: Dados da pesquisa

\subsubsection{Potencial de inovação}

$\mathrm{Na}$ BRAILE, os processos inerentes a esta subcategoria envolvem pesquisa aplicada e desenvolvimento experimental e, por fim, a busca da certificação (ANVISA). Sendo assim, os projetos de desenvolvimento de novos produtos requerem investimentos, gestão de riscos e planos contingenciais para projetos não exitosos, pois nem todo potencial de inovação identificado, a priori, é de fato convertido de forma bem-sucedida em produto para $\mathrm{o}$ mercado. Além disso, a BRAILE também atende demandas específicas de médicos, hospitais e universidades, como é o caso do desenvolvimento de endopróteses, que precisam ser customizadas ao biótipo do paciente.

Já no CREN, a preocupação com os processos de inovação guarda algumas semelhanças com a BRAILE, porém são mais flexíveis, pelo próprio tipo de serviço que é prestado. A identificação de oportunidades surge à medida que se olha para os indicadores de atendimento e, principalmente, para o campo, que é o norteador central do processo de inovação vigente no CREN. Alguns trechos das falas dos entrevistados ilustram tal situação:

A equipe está mais alinhada, então vamos fazer uma prototipagem, uma experimental. Então vai o coordenador do projeto, eu vou junto, vai o pessoal do suporte técnico. Às vezes, vai até o projetista que fez o desenho e que montou aquele produto. Então, durante a experimentação, está todo mundo sabendo, então aquela questão lá de ter antes apenas uma pessoa que trazia a informação, agora já tem mais usuários ali dentro, porque às vezes que tem que melhorar aquilo, porque aquilo não deu certo, ou entender melhor, aquilo deu certo por causa disso. Então, esse envolvimento maior, principalmente das pessoas que estão relacionadas a isso, contribuiu muito. (Código 4, da BRAILE)

Com a equipe da capacitação e do ambulatório também a gente conseguiu enxergar que, na verdade, as pessoas não estavam chegando aqui porque não tinham mais crianças com esse problema da má nutrição, mas não estavam chegando porque o serviço estava distante, porque as famílias, muitas famílias de alta vulnerabilidade também elas têm algumas questões sociais que não permitiam que elas chegassem aqui e aí a tomada de decisão foi: quem nós vamos atender no semiinternato? Qual é a população? Quem é o perfil? (Código 10, do CREN) 
Negócios de inovação social, de uma forma geral, apresentam escassez de recursos tangíveis, por isso os intangíveis são otimizados e estão mais presentes nos processos de inovação (Rosenbusch et al., 2011). No CREN, constatou-se essa situação: por depender de verbas e doações, a ênfase quanto à inovação está nas práticas de liderança participativa e nos processos e ferramentas para a gestão de ideias, que ocorrem a partir de reuniões regulares, pelos indicadores de resultados estabelecidos e pelo clima organizacional, que advém dessas ações todas.

\subsubsection{Processo}

O processo envolve a identificação e análise de oportunidade, seleção de ideias e desenvolvimento de tecnologias (significado que emergiu do campo). Na BRAILE, esse processo passou a ser mais eficaz e rápido, a partir do momento que ocorreu a implantação da política dos profissionais internos de $P \& D \& I$, que possibilitou que eles fossem até os clientes e o mercado em si. A empresa continua investindo em equipamentos modernos $\mathrm{e}$ relevantes para pesquisas e desenvolvimento dos produtos e parcerias com universidades de ponta, por meio de projetos de pesquisas. $\mathrm{Na}$ essência, o processo de inovação envolve pesquisa aplicada e desenvolvimento experimental na BRAILE e, por fim, a busca da certificação (ANVISA).

No CREN, a preocupação com os processos de inovação guarda algumas semelhanças com a BRAILE, porém são mais flexíveis, pelo próprio tipo de "serviço". A identificação e análise de oportunidades vão surgimento à medida que se olha para os indicadores de atendimento e, principalmente, para o campo, que é o norteador central dos resultados no CREN. As ações distintivas influenciam o processo de inovação no CREN, incluindo: (a) pesquisas científicas desenvolvidas em parceria com universidades (como o censo antropométrico); (b) a visita domiciliar para busca ativa de crianças desnutridas; e (c) intervenção no campo, no semi-internato e na cozinha experimental. Ressalta-se que a diversificação da receita e as atividades de comunicação interna e externa também são atividades que corroboram o processo de inovação.

\subsubsection{Resultado}

Especificamente, sobre os resultados da CI da BRAILE, em termos de desenvolvimento de produtos, destacaram-se: o novo oxigenador de membranas, um modelo mais compacto, que demandou uma quantidade menor de matériaprima, otimizando o seu preço de mercado; (b) a válvula cardíaca biológica, com vida útil ampliada (anticalcificante); e (c) a válvula Inovare, expansível por balão, montada sobre um cateter, que entra a partir da femoral e chega até o coração, para então fazer a liberação.

Em relação aos resultados da CI do CREN, destacaram-se: (a) prestação de serviços de saúde pública, em um prisma ampliado, envolvendo crianças e seu entorno familiar; (b) publicações técnicas e científicas para 
disseminação do conhecimento gerado, a partir das metodologias de intervenção desenvolvidas pelo CREN; e (c) formação, capacitação e atuação de equipes de projetos multidisciplinares (médicos, enfermeiros, nutricionistas, educadores físicos, pedagogos e psicólogos). Sendo assim, nota-se uma aderência desses resultados ao conceito de inovação social, ou seja, de metodologias que possibilitam a melhoria da qualidade de vida do outro e diminuem as desigualdades (Farfus \& Rocha, 2007).
Antes da apresentação propriamente dita do Framework, cabe retomar aqui os recursos fomentadores da $\mathrm{CI}$, com base no modelo adotado de Saunila and Ukko (2012). A CI não é uma estrutura única, mas sim, constituída de elementos distintos, porém complementares, que devem ser observados e gerenciados de forma holística (Lawson \& Samson, 2001; Saunila \& Ukko, 2014). Em virtude disso, um conjunto de fatores influência a sua dinâmica como é possível observar na Figura 8.

\section{Framework}

Figura 8 - Fatores intervenientes das subdivisões da CI baseado em Saunila and Ukko (2012)

\begin{tabular}{|c|l|l|}
\hline $\begin{array}{c}\text { Recurso Fomentador } \\
\text { da CI }\end{array}$ & \multicolumn{1}{|c|}{ Descrição } & \multicolumn{1}{|c|}{ Fatores Intervenientes } \\
\hline Potencial de Inovação & $\begin{array}{l}\text { Fatores que afetam e interferem na } \\
\text { capacidade atual de inovação da } \\
\text { empresa, podendo melhorá-la ou } \\
\text { piorá-la. }\end{array}$ & $\begin{array}{l}\text { Lideranças e processos decisórios, } \\
\text { estrutura organizacional e comunicação, } \\
\text { colaboração, cultura e clima } \\
\text { organizacional, criatividade e know-how. }\end{array}$ \\
\hline Processos de Inovação & $\begin{array}{l}\text { Entendidos como os sistemas e e } \\
\text { atividades que auxiliam na utilização } \\
\text { do potencial de inovação da empresa. }\end{array}$ & $\begin{array}{l}\text { Identificação e análise de oportunidades; } \\
\text { seleção de ideias e desenvolvimento de } \\
\text { tecnologias. }\end{array}$ \\
\hline Processos de Inovação & Inovação de produto e/ou serviço & $\begin{array}{l}\text { Algo novo ou relativamente melhorado, } \\
\text { que gere valor para a empresa ou seus } \\
\text { stakeholders. }\end{array}$ \\
\hline
\end{tabular}

Fonte: Elaborado pelos autores.

Os significados que emergiram do campo evidenciaram a presença de vários fatores intervenientes para a mobilização de recursos que fomentam a CI. Destaque para os sentimentos manifestados nas falas dos entrevistados, tanto na BRAILE como no CREN, que foram de admiração, forte identificação com os objetivos e valores das organizações em que atuam; forte desejo de manter-se nela; bem como disposição para exercer esforço considerável na busca de resultado inovadores, alavancando, assim, a CI dos negócios. 
A utilização do conhecimento especializado acumulado (know-how) no desempenho da função foi outro fator considerado relevante à $\mathrm{CI}$ dos negócios estudados. Uma equipe de projetos de P\&D\&I com elevado grau de qualificação, que se identifica com os valores do negócio em que atua, a busca pelo conhecimento, tanto acadêmico quanto prático, é feita de forma natural, por interesse e desejo pessoal. Obter isso, na sua rotina profissional diária, com apoio da organização, seja participando de treinamentos internos, de congressos, feiras e procedimentos cirúrgicos (BRAILE); seja cursando especializações externas, fazendo parte de treinamentos internos e reuniões (CREN), foi um dos motivos identificados como motivador para a permanência nos negócios investigados. Sendo assim, foi possível concluir que, equipe de projetos com elevado grau de know-how, alinhado à missão do negócio, tem interesse em aprender algo que possa auxiliá-la no desenvolvimento do seu trabalho, pois a motivação é intrínseca e pessoal.

Os resultados de inovação quando vão para o mercado, consequentemente vão para a sociedade e geram ciclicamente novos comportamentos, como ocorre no CREN, da equipe de projetos ir até à comunidade, "in loco", ou o Engenheiro de Projeto de P\&D\&I da BRAILE assistir um procedimento cirúrgico, é um processo que se retroalimenta, dentro das próprias categorias.
As contribuições dos FE para a mobilização de recursos fomentadores da $\mathrm{CI}$ dos negócios investigados, destacam-se: (a) otimização na percepção de oportunidades de negócio (novos produtos ou serviços de intervenção social) e do contato com os "clientes" e "sujeitos sociais" (médicos e crianças/família), ampliando o potencial de inovação; (b) atuação, com elevado grau de colaboração, minimizando os tradicionais conflitos entre os membros da equipe de projetos e alavancando o processo de inovação; (c) manifestação de admiração, respeito $\mathrm{e}$ aceitação das lideranças, percebendo coerência, justiça, capacitação técnica e comportamental na condução das atividades de $P \& D \& I$, o que facilita o processo de inovação; (d) utilização do know-how adquirido a partir de parcerias externas (médicos, hospitais e universidades), ampliando-o por meio da aquisição de novos conhecimentos e experiências e, promovendo a escalabilidade dos resultados das inovações geradas, sendo estas relacionadas ao NT e de natureza social no NIS.

Desta forma, com base nas análises realizadas foi possível propor um framework sobre o significado das contribuições dos FE para a mobilização de recursos fomentadores da CI, enfatizando-se os componentes de cada categoria de análise (Figura 9). 
Figura 9 - Framework sobre o significado das contribuições de FE para a mobilização de recursos fomentadores da CI

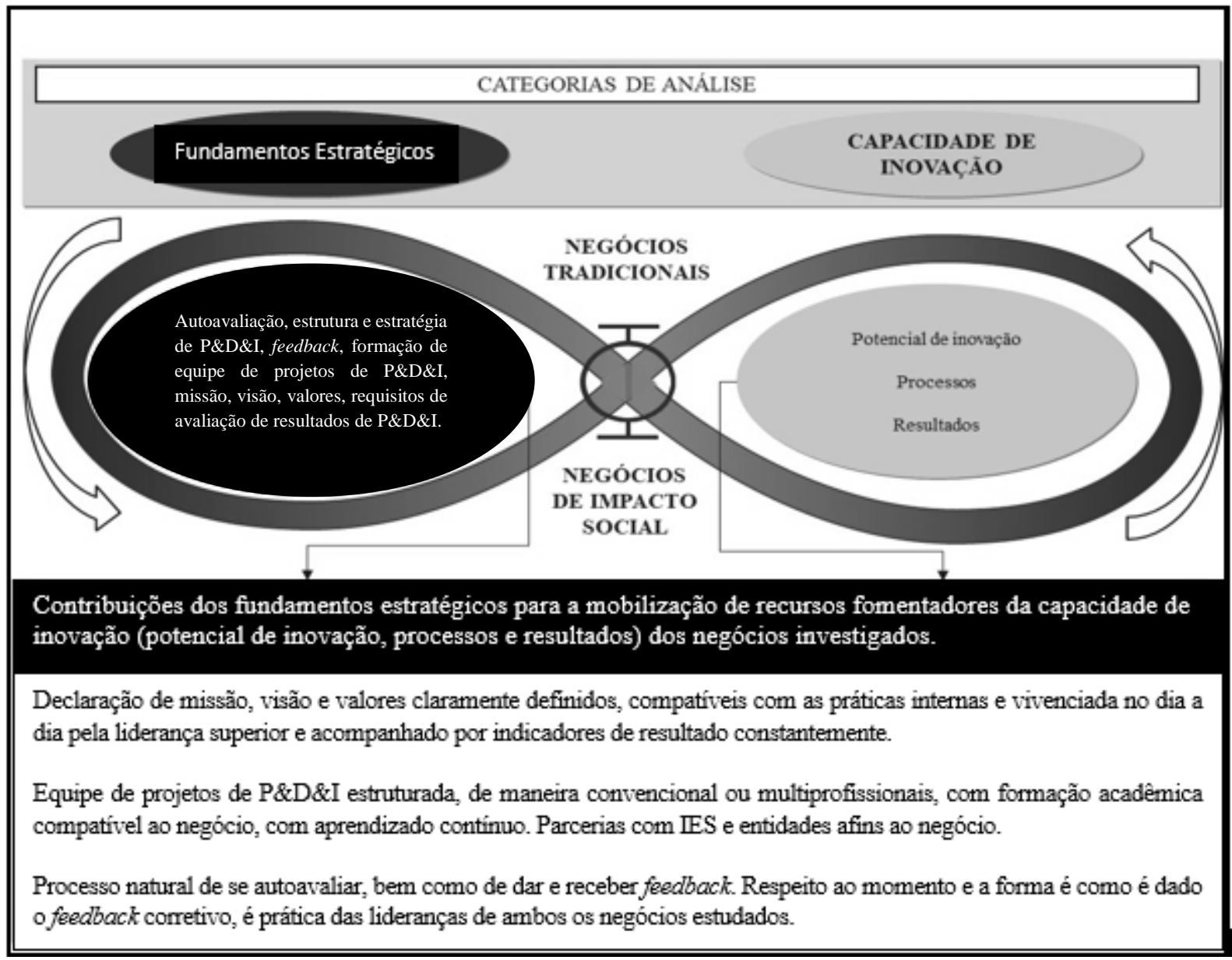

Fonte: Elaborada pelos autores, com auxílio do software Atlas Ti.

No Apêndice A estão explicados os componentes das categorias de análise e seus significados, bem como as distinções e similaridades de NT e NIS.

\section{6 - Considerações finais}

A partir da análise dos resultados, foi possível validar a proposição central desta pesquisa em investigar se as contribuições dos FE (missão, visão e valores) podem estimular a CI, tanto em NT, resultando em inovação tecnológica, quanto em NIS, promovendo a inovação social. Sendo assim, é possível identificar que os FE em todas as suas subdivisões, foram decisivos tanto para o negócio tradicional investigado (BRAILE), pois alavancaram o desenvolvimento de inovações tecnológicas, como também foram importantes para o negócio de impacto social investigado (CREN), promovendo o valor social e, com ele, as inovações sociais.

$$
\text { Vale destacar que quanto à }
$$
caracterização das dimensões (Potencial de Inovação, Processos e Resultados) da capacidade de inovação de negócios tradicionais e de impacto social, observaram-se 
características praticamente semelhantes, no que diz respeito à relevância no processo. $\mathrm{Na}$ prática diária, porém, devido às peculiaridades dos negócios, houve algumas distinções.

\section{A BRAILE (inovação tecnológica)} exige uma estrutura organizacional direcionada para as várias etapas do processo, desde a identificação da necessidade no mercado, passando pelo desenvolvimento, fabricação e comercialização. Uma equipe de P\&D\&I altamente especializada é necessária, sendo que a figura do mentor do negócio, presente no dia a dia, influencia e mantém acesa a chama da ideologia que deu início ao negócio. No CREN (inovação social) decisões quanto à estrutura, processos, equipe e parcerias, são tomadas a partir da compilação dos dados obtidos em reuniões e os diversos indicadores de resultados, estabelecidos em praticamente todos os departamentos. Medir, acompanhar e ajustar, com base na realidade, ou seja, intervir no campo, é incumbência da liderança.

Importante informar que o fato da BRAILE e do CREN terem suas declarações de missão "escritas" e informadas para a equipe de projetos, por si só não garante o alcance dos resultados propostos, nem mesmo o desenvolvimento e inovação do negócio. Em ambos os negócios, é importante um interesse genuíno por parte das lideranças superiores, atuando baseadas nos valores definidos em suas declarações.

A formação acadêmica da equipe de projetos de P\&D\&I, outro aspecto dos FE pesquisados, também evidenciou ser um diferencial fomentador da CI. Na BRALIE, a formação acadêmica e a capacitação técnica em engenharia mecânica e biomedicina é o que prevalece na equipe de projetos de P\&D\&I com ênfase em atividades de pesquisas científicas internas e externas. Já no CREN, a formação acadêmica tem origem multidisciplinar (medicina, nutrição, psicologia, pedagogia etc.), pois são as competências que têm relação com o negócio, envolvendo o atendimento à criança e à família, que extrapola a questão da nutrição. A pesquisa científica tanto interna como externa também é significativa para o alcance dos objetivos propostos. É possível informar que ter uma equipe de projetos de P\&D\&I com formação acadêmica e técnica alinhada ao negócio, contando com pesquisa científica com recursos internos e externos, fomenta a CI da organização. Essa constatação é relevante para a definição de práticas de gestão de pessoas nas organizações, desde recrutamento, seleção, treinamento e programas de desenvolvimento e carreira.

A última subdivisão da categoria $\mathrm{FE}$, os processos de feedback e autoavaliação, também se mostraram como prática regular entre a equipe de projetos de $\mathrm{P} \& D \& I$ pesquisada. Ter clareza do resultado esperado, da disponibilidade de recursos necessários para tal, num ambiente que há coerência entre prática e discurso de valores esperados, favorece a formação de um clima organizacional saudável e motivador, na qual os funcionários querem se manter ligados. Para tal, de forma geral, autoavaliar ou considerar feedback externo, são 
formas de elevar as chances de se manter na organização, através da adequação de comportamentos. Tanto na BRAILE como no CREN, os atores entrevistados manifestaram de forma natural o feedback, bem como a autoavaliação frequente.

As contribuições para o avanço do conhecimento se devem à apresentação de dados empíricos para desmistificar que negócios de impacto social não precisam de uma estrutura organizacional estabelecida, como ocorre nos negócios tradicionais (com fins lucrativos). Ter uma causa apenas não garante comprometimento e resultados.

Esta pesquisa limita-se pelo número reduzido de NT e NIS investigados, além do fato de serem negócios que, a princípio, já são diferenciados dos demais em sua categoria devido aos prêmios recebidos (FINEP e Empreendedor Social), e de destaque nos seus segmentos, evidenciando, com isso, a sua distinção. Seria interessante, para contrapor essa limitação, que a mesma pesquisa fosse feita em uma empresa também no segmento da área de saúde, de base tecnológica, que não fosse ganhadora de prêmios de inovação. Para estudos futuros recomendamos realizar a pesquisa em outros negócios de impacto social, em segmentos diferentes, tais como educação, segurança e sustentabilidade, com demandas sociais ainda negligenciadas, em países em desenvolvimento, como o Brasil.

\section{Referências}

Afuah, A. (2002). Mapping Technological Capabilities into Product Markets and Competitive Advantage: The Case of Cholesterol Drugs. Strategic Management Journal, 23(2), 171-9. https://doi.org/10.1002/smj.221

Aithal, P. S. (2016). Creating Innovators through setting up organizational Vision, Mission and Core Values: A Strategic Model in Higher Education. International Journal of Management, IT and Engineering, 6(1), 310-324. http://doi.org/10.5281/zenodo.161147

Austin, J., Stevenson, H., \& Wei-Skillern, J. (2006). Social and Commercial Entrepreneurship: Same, Different, or Both? Entrepreneurship Theory and Practice, 30(1), 1-22. https://doi.org/10.1111/j.15406520.2006.00107.x

Barney, J. (1991). Firm resources and sustained competitive advantage. Journal of Management, 17(1), 99-120. https://doi.org/10.1177/01492063910170010 8

Bartkus, B. R., Glassman, M., \& McAfee, R. B. (2000). Mission statements: are they smoke and mirrors? Business Horizons, 43 (6), 23-28. https://doi.org/10.1016/S00076813(00)80018-X

Bartkus, B. R., \& Myron, G. (2008). Do firms practice what they preach? The relationship between mission statements and stakeholder management. Journal of Business Ethics, 83(2), 207-216. https://doi.org/10.1007/s10551-007-9612-0

Bignetti, L. P. (2011). As inovações sociais: uma incursão por ideias, tendências e focos de pesquisa. Ciências Sociais Unisinos, 47(1). Recuperado de http://www.redalyc.org/resumen.oa?id=938 20778002. https://doi.org/10.4013/1040

Brătianu, C., \& Bălănescu, G. V. (2008). Vision, mission, and corporate values. A comparative analysis of the top 50 U.S. 
companies. Management \& Marketing, 3(3), 19-38.

https://ideas.repec.org/a/eph/journl/v3y2008 i3n2.html

Cajaiba-Santana, G. (2014). Social innovation: Moving the field forward. A conceptual framework. Technological Forecasting and Social Change, 82(Supplement C), 42-51. https://doi.org/10.1016/j.techfore.2013.05.0 08

Camelo, O., C., García, C, J., Sousa, G., E., \& Valle, C., R. (2011). The influence of human resource management on knowledge sharing and innovation in Spain: the mediating role of affective commitment. The International Journal of Human Resource Management, 22(07), 1442-1463. https://doi.org/10.1080/09585192.2011.5619 60

Cooper, R. G., \& Edgett, S. J. (2009). Lean, Rapid and Profitable New Product Development. Stage-Gate International.

Creswell, J. W. (2007). Projeto de pesquisa: métodos qualitativo, quantitativo e misto (2nd ed.). Artmed.

Crossan, M. M., \& Apaydin, M. (2010). A multi-dimensional framework of organizational innovation: a systematic review of the literature. Journal of Management Studies, 47(6), 1154-91. https://doi.org/10.1111/j.14676486.2009.00880.x

Damanpour, F., \& Gopalakrishnan, S. (2001). The Dynamics of the adoption of product and process innovations in organizations. Journal of Management Studies, 38(1), 4565. https://doi.org/10.1111/14676486.00227

Desmidt, S., Prinzie, A., \& Decramer, A. (2011). Looking for the value of mission statements: a meta-analysis of 20 years of research. Management Decision, 49(3), 468-483. https://doi.org/10.1108/00251741111120806

Farfus, D., \& Rocha, M. C. D. S. (2007).
Inovação Social: um conceito em construção. Inovações Sociais. SESI/SENAI/IEL/UNINDUS.

Godoy, A. S. (1995a). Introdução à pesquisa qualitativa e suas possibilidades. Revista de Administração de Empresas, 35(2), 57-63. http://dx.doi.org/10.1590/S003475901995000200008

Godoy, A.S. (1995b). Pesquisa qualitativa: tipos fundamentais. Revista de Administração de empresas, 35(3), 20-29. http://dx.doi.org/10.1590/S003475901995000300004

Gopalakrishnan, S., \& Damanpour, F. (1997). A review of innovation research in economics, sociology and technology management. Omega, 25(1), 15-28. https://doi.org/10.1016/S03050483(96)00043-6

Ireland, D. R., \& Hitt, M. A. (1992). Mission statements: importance, challenge. Business Horizons 35(3), $34-42$. https://doi.org/10.1016/00076813(92)90067-J

Kirner, E., Kinkel, S., \& Jaeger, A. (2009). Innovation paths and the innovation performance of low-technology firms - an empirical analysis of German industry. Research Policy, 38(3) 447-458. https://doi.org/10.1016/j.respol.2008.10.011

Lawson, B., \& Samson, D. (2001). Developing innovation capability in organisations: a dynamic capabilities approach. International Journal of Innovation Management, 5(3), 377-400. https://doi.org/10.1142/S136391960100042 7

Martins, G. de A., \& Theóphilo, C. R. (2009). Metodologia da investigação científica para ciências sociais aplicadas. Atlas.

Minayo, M. C. de S. (2011). Pesquisa social: teoria, método e criatividade. Editora Vozes Ltda.

Mone, M. A., McKinley, W., \& Barker III, V. 
L. (1998). Organizational decline and innovation: a contingency framework. Academy of Management Review, 23(1), 115-32. https://doi.org/10.2307/259102

Mulgan, G., Tucker, S., Ali, R., \& Sanders, B. (2007). Social innovation: what it is, why it matters and how it can be accelerated. The Young Foundation.

https://youngfoundation.org/wpcontent/uploads/2012/10/Social-Innovationwhat-it-is-why-it-matters-how-it-can-beaccelerated-March-2007.pdf

Neely, A., Filippini, R., Forza, C., Vinelli, A. and Hii, J. (2001). A framework for analyzing business performance, firm innovation, and related contextual factors: perceptions of managers and policy makers in two European regions. Integrated Manufacturing Systems, 12(2), 114-124. https://doi.org/10.1108/09576060110384307

Neely, A., \& Hii, J. (1998). Innovation and Business Performance: A Literature Review. The Judge Institute of Management Studies. Cambridge.

http://ecsocman.hse.ru/data/696/521/1221/lit review_innov1.pdf

Patel, B. S, Booker, L.D., Ramos, M., \& Bart, C. (2015). Mission statements and performance in non-profit organisations. Corporate Governance, 15(5): 759-774. https://doi.org/10.1108/CG-07-2015-0098

Paulus, T. M., Pope, E. M., Woolf, N., \& Silver, C (2019). It will be very helpful once I understand ATLAS.ti: Teaching ATLAS.ti using the FiveLevel QDA method. International Journal of Social Research Methodology, 22(1), 1-18. https://doi.org/10.1080/13645579.2018.1510 662

Phillis, W., Lee, H., Ghobadian, A., O'Regan, N., \& James, P. (2015). Social Innovation and Social Entrepreneurship: A Systematic Review. Group \& Organization Management, 40(3). https://doi.org/10.1177/1059601114560063

Ravichandran, T. (2018). Exploring the relationships between IT competence, innovation capacity and organizational agility. The Journal of Strategic Information Systems, 27 (1) (2018), 22-42. https://doi.org/10.1016/j.jsis.2017.07.002

Reichert, F. M., Camboim, G. F., \& Zawislak, P. A. (2015). Capacidades e trajetórias de inovação de empresas brasileiras. Revista de Administração Mackenzie, 16(5), 161-194. http://www.spell.org.br/documentos/ver/381 33/capacidades-e-trajetorias-de-inovacaode-empresas-brasileiras

Rokeach, M. (1973). The nature of human values. New York: The Free Press.

Rosenbusch, N., Brinckmann, J., \& Bausch, A. (2011). Is innovation always beneficial? A meta-analysis of the relationship between innovation and performance in SMEs. Journal of Business Venturing, 26(4), 441457.

https://doi.org/10.1016/j.jbusvent.2009.12.0 02

Santos, F. M. (2012). A positive theory social entrepreneurship. Journal of Business Ethics, 111(3), 335-351. http://dx.doi.org/10.2139/ssrn.1553072

Saunila, M., \& Ukko, J. (2012). A conceptual framework for the measurement of innovation capability and its effects. Baltic Journal of Management, 7(4), 355-375. https://doi.org/10.1108/17465261211272139

Saunila, M., Pekkola, S., \& Ukko, J. (2014). The relationship between innovation capability and performance: The moderating effect of measurement. International Journal of Productivity and Performance Management, 63(2), 234-249. https://doi.org/10.1108/IJPPM-04-20130065

Saunila, M., \& Ukko, J. (2014). Intangible aspects of innovation capability in SMEs: Impacts of size and industry. Journal of Engineering and Technology Management, 33, 32-46. https://doi.org/10.1016/j.jengtecman.2014.0 2.002 
Schumpeter, J. A. (1961). The Theory of Economic Development: An Inquiry into Profits, Capital, Credit, Interest, and the Business Cycle (1912/1934). https://cambridgeforecast.wordpress.com/20 07/12/page/7/

Tidd, J., \& Bessant, J. (2008). Gestão da inovação. (5nd ed.) Porto Alegre, RS: Bookman Editora.

Triviños, A. N. S. (1987). Introdução à pesquisa em ciências sociais: a pesquisa qualitativa em educação: o positivismo, a fenomenologia, o Marxismo. Atlas.

Voorberg, W. H., Bekkers, V. J. J. M., \&

Tummers L. G. (2015). A Systematic

Review of Co-Creation and Co-Production:

Embarking on the social innovation journey,

Public Management Review, 17(9), 1333-
1357.

https://doi.org/10.1080/14719037.2014.9305 05

Yin, R. (2001). Metodologia de Estudos de Caso. Bookman.

Zawislak, P. A., Alves, A. C., Tello-Gamarra, J., Barbieux, D., \& Reichert, F. M. (2012). Innovation capability: from technology development to transaction capability. Journal of Technology Management \& Innovation, 7(2), 14-27. http://dx.doi.org/10.4067/S071827242012000200002

APÊNDICE A

\begin{tabular}{|c|c|c|c|}
\hline \multirow[t]{2}{*}{ Componentes } & \multicolumn{2}{|c|}{ Distinção } & \multirow[t]{2}{*}{ Similaridades } \\
\hline & NT & NIS & \\
\hline $\begin{array}{l}\text { (1) Autoavaliação } \\
\text { (Envolve a realização } \\
\text { de avaliação sobre si } \\
\text { mesmo, como forma } \\
\text { de autoconhecimento) }\end{array}$ & $\begin{array}{l}\text { Já faz parte do repertório de } \\
\text { comportamento da equipe de } \\
\text { projetos de P\&D\&I a prática } \\
\text { de fazer autoavaliação, pois } \\
\text { por atuarem por projetos e } \\
\text { saberem da importância do } \\
\text { conhecimento, se policiam } \\
\text { para evitar atuar no "piloto } \\
\text { automático". }\end{array}$ & $\begin{array}{l}\text { A prática da autoavaliação } \\
\text { também é presente, pois } \\
\text { atuam com pessoas, com } \\
\text { perfis diferentes, o que exige } \\
\text { de cada profissional sair do } \\
\text { "piloto automático", revendo } \\
\text { suas crenças e valores e } \\
\text { adequar o seu comportamento } \\
\text { àquele paciente em especial. }\end{array}$ & $\begin{array}{l}\text { Os profissionais da } \\
\text { equipe de projetos de } \\
\text { P\&D\&I manifestaram } \\
\text { uma postura de } \\
\text { humildade, ou seja, que } \\
\text { não são donos da verdade } \\
\text { e que eventualmente } \\
\text { podem entrar em conflito } \\
\text { entre o que acham que } \\
\text { devem fazer e o que deve } \\
\text { ser feito. Por este motivo } \\
\text { se permitem } \\
\text { autoavaliação a como } \\
\text { processo natural. }\end{array}$ \\
\hline $\begin{array}{l}\text { (2) Estrutura e } \\
\text { estratégia de P\&D\&I } \\
\text { - o potencial de } \\
\text { inovação dos } \\
\text { negócios está } \\
\text { associado à estrutura } \\
\text { de P\&D\&I. }\end{array}$ & $\begin{array}{l}\text { O departamento de P\&D\&I } \\
\text { é composto por profissionais } \\
\text { especializados, com } \\
\text { estrutura tradicional com } \\
\text { gerência e áreas específicas } \\
\text { para cada assunto. Contam } \\
\text { com parcerias com } \\
\text { universidades do Brasil e até }\end{array}$ & $\begin{array}{l}\text { Não há uma estrutura formal } \\
\text { tradicional de P\&D\&I, mas } \\
\text { sim profissionais de } \\
\text { diferentes especialidades } \\
\text { que fazem essa função, que } \\
\text { atendam à causa-fim, } \\
\text { nutrição, que sofre } \\
\text { influência multifatorial. } \\
\text { Contam, também, com }\end{array}$ & Parcerias \\
\hline
\end{tabular}




\begin{tabular}{|c|c|c|c|}
\hline & $\begin{array}{l}\text { do exterior, além dos } \\
\text { médicos e laboratórios. }\end{array}$ & $\begin{array}{l}\text { parcerias com universidades } \\
\text { e órgãos públicos, como } \\
\text { Postos de saúde, na } \\
\text { identificação, aplicação e } \\
\text { acompanhamento dos } \\
\text { tratamentos. }\end{array}$ & \\
\hline $\begin{array}{l}\text { (3) Feedback - Trata- } \\
\text { se do retorno sobre o } \\
\text { desempenho de um } \\
\text { colaborador, } \\
\text { proporcionando um } \\
\text { parecer sobre um } \\
\text { trabalho realizado, } \\
\text { sendo assim, sua } \\
\text { aplicação contributiva } \\
\text { e orientadora. }\end{array}$ & $\begin{array}{l}\text { A liderança oferece } \\
\text { feedbacks constantes e } \\
\text { oportunos, elogiando em } \\
\text { público e, nos casos de } \\
\text { pontos de melhorias, erros } \\
\text { ou não conformidades, esses } \\
\text { são apresentados de forma } \\
\text { particular. }\end{array}$ & $\begin{array}{l}\text { como várias áreas têm } \\
\text { contato com a criança e } \\
\text { familiares, e cada detalhe } \\
\text { desse contato é significativo } \\
\text { no tratamento, esses } \\
\text { profissionais e os da equipe } \\
\text { de projetos de P\&D\&I } \\
\text { entrevistados, já têm entre si } \\
\text { a cultura de dar e receber } \\
\text { feedback, tanto da parte da } \\
\text { liderança, como das áreas } \\
\text { que fazem parte da cadeia. }\end{array}$ & $\begin{array}{l}\text { O feedback é visto de } \\
\text { forma natural, como } \\
\text { sendo positivo e que } \\
\text { favorece o bom resultado. }\end{array}$ \\
\hline $\begin{array}{l}\text { (4) Formação de } \\
\text { Equipe de projetos de } \\
\text { P\&D\&I: Entenda-se, } \\
\text { para efeito desse } \\
\text { trabalho, formação } \\
\text { acadêmica da equipe } \\
\text { de P\&D\&I associada } \\
\text { ao potencial de } \\
\text { inovação. }\end{array}$ & $\begin{array}{l}\text { A equipe de projetos de } \\
\text { P\&D\&I possui formação } \\
\text { superior em Engenharia } \\
\text { Mecânica, na sua maioria, } 1 \\
\text { em Biomedicina e } 1 \text { em } \\
\text { Biofísica. Grande parte está } \\
\text { com mestrado (completo ou } \\
\text { andamento). }\end{array}$ & $\begin{array}{l}\text { A equipe de projetos de } \\
\text { P\&D\&I, na sua maioria } \\
\text { também possui nível superior, } \\
\text { alguns com mestrado e } \\
\text { doutorado, porém com } \\
\text { formações distintas e } \\
\text { relacionados à causa fim da } \\
\text { entidade, nutrição. Por ser } \\
\text { uma condição multifatorial, } \\
\text { atuam na equipe de projetos } \\
\text { de P\&D\&I: médica, } \\
\text { nutricionista, psicóloga, } \\
\text { pedagoga etc. }\end{array}$ & $\begin{array}{l}\text { O } \\
\text { acadêmico, onhecimento } \\
\text { para o negócio, está } \\
\text { presente nas duas } \\
\text { equipes, cada um com a } \\
\text { sua peculiaridade. A } \\
\text { maioria r continua } \\
\text { estudando e participante } \\
\text { de congressos e pesquisas } \\
\text { científicas. }\end{array}$ \\
\hline $\begin{array}{l}\text { (5) Missão, Visão e } \\
\text { valores - saber qual } \\
\text { seu negócio, como } \\
\text { vislumbra o futuro e } \\
\text { que valores nortearão } \\
\text { o negócio. }\end{array}$ & $\begin{array}{l}\text { A Missão, Visão e Valores } \\
\text { são de conhecimento de } \\
\text { todos que se identificam e } \\
\text { seguem as premissas } \\
\text { definidas. O fundador dá } \\
\text { "vida" ao texto, enaltecendo } \\
\text { a missão e valores e atuando } \\
\text { de acordo com o que prega. } \\
\text { Todos da equipe de projetos } \\
\text { vibram ao falar da missão e } \\
\text { o quanto se sentem honrados } \\
\text { em atuar na empresa. }\end{array}$ & $\begin{array}{l}\text { A vibração é movida pela } \\
\text { causa em si (recuperar } \\
\text { crianças subnutridas). Não há } \\
\text { o fundador lembrando a } \\
\text { missão, mas gestores } \\
\text { acompanhando os resultados } \\
\text { através de indicadores, } \\
\text { envolvendo todas as áreas nas } \\
\text { decisões. }\end{array}$ & 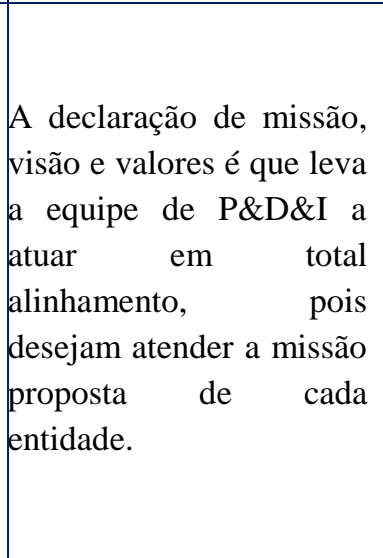 \\
\hline
\end{tabular}




\begin{tabular}{|c|c|c|c|}
\hline $\begin{array}{l}\text { (6) Requisitos de } \\
\text { Avaliação dos } \\
\text { Resultados de } \\
\text { P\&D\&I - São os } \\
\text { requisitos para se } \\
\text { avaliar o potencial de } \\
\text { inovação dos } \\
\text { resultados de P\&D\&I. }\end{array}$ & $\begin{array}{l}\text { A avaliação do resultado é o } \\
\text { registro na ANVISA ou } \\
\text { abertura do Cadastro. }\end{array}$ & $\begin{array}{l}\text { A avaliação do resultado se dá } \\
\text { pelo número de crianças que } \\
\text { obtém alta por terem saído da } \\
\text { linha da subnutrição. }\end{array}$ & $\begin{array}{l}\text { Apresentam dados } \\
\text { quantificáveis de alcance } \\
\text { dos resultados, sendo que } \\
\text { no NT } \\
\text { acompanhamento } \\
\text { continua ao se verificar a } \\
\text { aceitação do produto no } \\
\text { mercado considerando o } \\
\text { retorno financeiro das } \\
\text { vendas. No NIS a } \\
\text { continuidade se dá através } \\
\text { da disseminação do } \\
\text { conhecimento através dos } \\
\text { programas da família, } \\
\text { qualificação dos agentes } \\
\text { de saúde e distribuição } \\
\text { gratuita de literatura } \\
\text { específica para escolas. }\end{array}$ \\
\hline $\begin{array}{l}\text { (7) Potencial de } \\
\text { Inovação: Envolve } \\
\text { liderança e processo } \\
\text { decisório; estrutura } \\
\text { organizacional e } \\
\text { comunicação; } \\
\text { colaboração, cultura e } \\
\text { clima organizacional; } \\
\text { criatividade } \\
\text { individual e know- } \\
\text { how. }\end{array}$ & $\begin{array}{l}\text { O potencial de inovação é } \\
\text { evidenciado a partir de } \\
\text { elementos internos de } \\
\text { liderança empreendedora, de } \\
\text { profissionalização do } \\
\text { negócio e qualificação e } \\
\text { envolvimento das lideranças } \\
\text { e dos liderados, bem como } \\
\text { de elementos externos } \\
\text { relacionados à cocriação de } \\
\text { inovações com parceiros e } \\
\text { concorrência com grandes } \\
\text { multinacionais. }\end{array}$ & $\begin{array}{l}\text { O potencial de inovação é } \\
\text { evidenciado externamente, ou } \\
\text { seja, no campo, com vistas a } \\
\text { prospectar in loco os diversos } \\
\text { espectros dos problemas } \\
\text { sociais. }\end{array}$ & - \\
\hline $\begin{array}{l}\text { (8) Processos: } \\
\text { Envolve a } \\
\text { identificação e análise } \\
\text { de oportunidades; } \\
\text { seleção de ideias; e } \\
\text { desenvolvimento de } \\
\text { tecnologias. }\end{array}$ & $\begin{array}{l}\text { O processo de inovação é } \\
\text { evidenciado a partir de } \\
\text { elementos internos de } \\
\text { pesquisa aplicada, } \\
\text { desenvolvimento } \\
\text { experimental e busca de } \\
\text { certificação (ANVISA), } \\
\text { resultando em produtos } \\
\text { padronizados ou } \\
\text { customizados, bem como de } \\
\text { elementos colaborativos, } \\
\text { relacionados a parcerias com } \\
\text { universidades para } \\
\text { desenvolvimento } \\
\text { pesquisas científicas. de }\end{array}$ & $\begin{array}{l}\text { O processo de inovação é } \\
\text { evidenciado de forma } \\
\text { colaborativa, ou seja, com a } \\
\text { visita domiciliar para busca } \\
\text { ativa de crianças desnutridas } \\
\text { e com a intervenção direta no } \\
\text { campo, no semi-internato e na } \\
\text { cozinhar experimental, } \\
\text { destacando-se também as } \\
\text { pesquisas científicas } \\
\text { desenvolvidas em parceria } \\
\text { com universidades, } \\
\text { resultando em metodologias } \\
\text { de intervenção de saúde } \\
\text { pública. }\end{array}$ & - \\
\hline
\end{tabular}




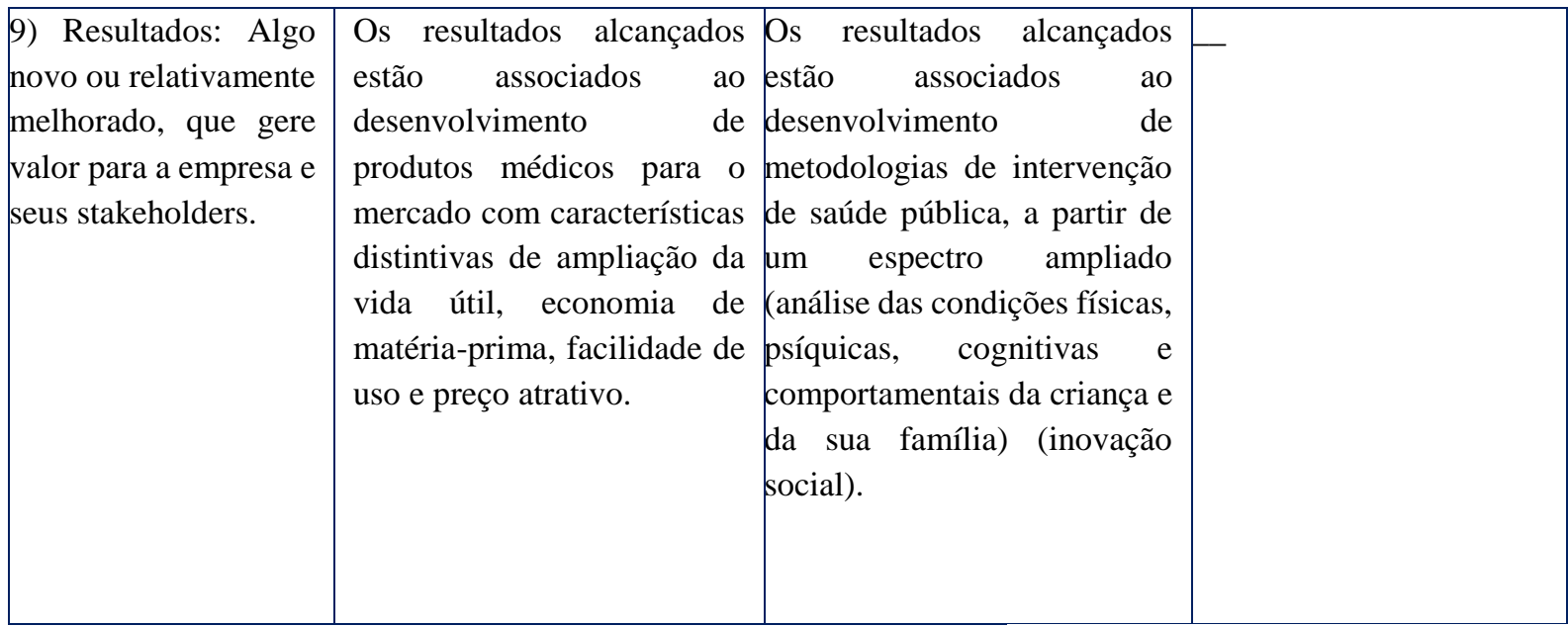

Fonte: Elaborada pelos autores, com auxílio do software Atlas Ti. Nota: Componentes de 1 até 6 são da categoria "FE"; Componentes de 7 até 9 são da categoria "CI". 